\title{
Numerical Modelling of Mixture Formation and Combustion in DISI Hydrogen Engines with Various Injection Strategies
}

\author{
A. Hamzehloo and P.G. Aleiferis \\ University College London, UK
}

Copyright (C) 2014 SAE International

\begin{abstract}
International obligations to reduce carbon dioxide emissions and requirements to strengthen security of fuel supply, indicate a need to diversify towards the use of cleaner and more sustainable fuels. Hydrogen has been recommended as an encouraging gaseous fuel for future road transportation since with reasonable modifications it can be burned in conventional internal combustion engines without producing carbon-based tailpipe emissions. Direct injection of hydrogen into the combustion chamber can be more preferable than port fuel injection since it offers advantages of higher volumetric efficiency and can eliminate abnormal combustion phenomena such as backfiring. The current work applied a fully implicit computational methodology along with the Reynolds-Averaged Navier-Stokes (RANS) approach to study the mixture formation and combustion in a direct-injection spark-ignition engine with hydrogen fuelling. Hydrogen was issued into the combustion chamber by a six-hole side-mounted injector. The effects of two injection strategies, namely single and double-pulse injections per cycle, were examined whilst maintaining an equivalence ratio of 0.5 at part-load conditions of 0.5 bar intake pressure at 1,000 RPM. The combustion process was also computed using a 'partially-premixed homogeneous reactor' approach in conjunction with a detailed chemical kinetics combustion solver. The results were discussed in relation to previously published work on in-cylinder experiments of hydrogen engines.
\end{abstract}

\section{Introduction}

\section{Hydrogen-Fuelled IC Engines}

International commitment to reduced carbon-based emissions as well as requirements to strengthen security of fuel supply indicates a need to diversify towards use of sustainable reduced-carbon fuels. A number of liquids and gases have been suggested as alternative future fuels for internal combustion (IC) engines; among them, gaseous hydrogen $\left(\mathrm{H}_{2}\right)$ has the potential to provide a promising long-standing solution [1-3]. Hydrogen combustion leads to total absence of Particulate Matter (PM), Unburned Hydro-Carbons (UHC), CO and $\mathrm{CO}_{2}$ tailpipe emissions. Another significant benefit of hydrogen is that it can potentially be produced on an industrial scale using sustainable methods such as electrolysis, water splitting, nuclear thermochemical cycles, radiolytic splitting,

Page 1 of 21 photo-chemical and photo-bio-chemical processes, biological methods from agricultural residuals and anthropogenic wastes, plasma reforming, and dark fermentation [4-7].

Hydrogen has several exceptional properties which makes it an excellent fuel for satisfactory performance in IC engines and without the cost penalty related to hydrogen fuel cell technology. It has a wide range of flammability that can lead to very low $\mathrm{NO}_{\mathrm{x}}$ emissions simply by operating under lean conditions of $\Phi \leq 0.5$ [8]. Furthermore, the autoignition temperature of hydrogen is relatively high. This allows larger compression ratios to be used for efficiency enhancement. The Lewis number $(L e)$ of hydrogen is lower than that of most conventional fuels due to its high diffusion coefficient and thermal conductivity which contribute substantially to some combustion characteristics that are particular to hydrogen [910]. The laminar flame speed of hydrogen is almost one order of magnitude higher than that of conventional hydrocarbon fuels. This results in fast energy release rates around top dead center (TDC) and consequently higher power output and efficiency. However, for very lean mixtures, the laminar flame speed of hydrogen decreases significantly. The fast burning characteristics of hydrogen result in low sensitivity of the engine performance to changes in the shape of the combustion chamber, level of turbulence, as well as intake air motion [11]. Further information on hydrogen's unique properties can be obtained from references [11-12].

Besides the aforementioned beneficial characteristics of hydrogen, there are various challenges associated with hydrogen IC engines. Hydrogen has a low heating value on volume basis which results in reduced power output particularly under lean operating conditions and, especially, in naturally aspirated engines. Hydrogen IC engines can also face serious problems associated with abnormal combustion modes such as pre-ignition and backfiring into the intake manifold. Hydrogen's low minimum ignition energy (less than one tenth that of gasoline) and also its small quenching distance contribute to such abnormalities [12-14]. Pre-ignition and backfiring typically occur together; in fact, backfire occurs when the air-fuel mixture is ignited during the intake stroke by heat sources before getting ignited by the spark (e.g. by the hot spark electrodes and/or lubricant deposits), resulting in combustion in the intake manifold. Another challenging issue related to hydrogen IC engines is knocking combustion [1516]. Employing a suitable injection strategy and spark timing can eliminate most of the issues related to hydrogen's abnormal combustion modes and at the same time increase 
engine efficiency. The following section aims to describe the influence of the injection strategy on performance characteristics of hydrogen-fuelled IC engines.

\section{Hydrogen Injection Strategies}

Port fuel injection (PFI) [17-22] and in-cylinder Direct Injection (DI) [22-29] of hydrogen are both options for hydrogen-fuelled IC engines. High pressure DI after intake valves closure is believed to be the most preferable approach as it can eliminate pre-ignition and backfire, as well as overcome the volumetric efficiency losses associated with hydrogen's low density and air displacement when introduced by PFI. Hence DI can lead to the same, or even a higher, volume specific power than that of conventional gasoline engines.

DI also provides great flexibility in selecting injection strategies of different timing and duration, different injection pressure, injector location and injector nozzle configuration. An optimum DI strategy can have a significant effect on mixture formation and improve both combustion quality and pollutant formation. Wallner et al [23] experimentally investigated the effects of different injector nozzle configurations (6-hole symmetric and 5 -hole asymmetric injectors) and locations (central and sidemounted injectors with hole pointed towards either the piston crown or the spark plug). According to their work, the injector's location and nozzle design had a significant effect on the indicated thermal efficiency, particularly at low-load conditions with $\sim 4 \%$ higher efficiency for the side mounted injectors than for the centrally located ones. Additionally, it was found that at high-load conditions, using side-mounted configurations resulted in reduction of $\mathrm{NO}_{x}$ emissions. Wallner et al [23] also examined different injection timings. It was observed that the $10-90 \%$ mass fraction burned duration decreased as the start of injection (SOI) timing was retarded. Moreover it was observed that the burn duration for a fixed SOI could decrease by $\sim 50 \%$ if the hydrogen jets were directed towards the spark plug rather than the piston. Endoscopic work showed that this was mainly due to the formation of a rich mixture zone near the spark plug for the former configuration in comparison to a more homogeneous mixture obtained with the latter. Such studies can also explain how selecting an appropriate injection timing and location can control combustion and even the onset of knocking in hydrogen engines.

Kaiser and White [24] studied the effect of different injection timings on mixture formation in an optical hydrogen IC research engine. They used a side-mounted injector with 6 symmetric nozzles (with jets directed towards both the spark plug and the piston) and injection duration of $50{ }^{\circ} \mathrm{CA}$ at 1200 RPM. Three different SOI timings were employed; $112^{\circ} \mathrm{CA}$, $90^{\circ} \mathrm{CA}$, and $77.5^{\circ} \mathrm{CA}$ before top dead center (BTDC). It was found that for early injection timing (112 ${ }^{\circ}$ CA BTDC), hydrogen's jets changed the in-cylinder flow and the velocity magnitude increased considerably compared to a non-fuelled flow field. Intermediate and late injection timings $\left(90^{\circ} \mathrm{CA}\right.$, and $77.5^{\circ} \mathrm{CA}$ BTDC) produced fairly similar flow fields that were found to be greatly affected by the hydrogen jet-wall interactions. Based on their study it was noticed that for the early injection timing, the air-hydrogen charge was essentially premixed, whereas for the intermediate and late injection timings the rich and lean regions were separated by a mixing region with sharp gradients. The studies of Wallner et al [23] and Kaiser and White [24] showed that SOI and its retarding Page 2 of 21 should be adjusted carefully based on various important parameters, including engine geometry and injector design, in order to avoid formation of highly inhomogeneous mixtures at ignition timing.

Salazar and Kaiser [25] conducted a series of optical experiments on the influence of $\mathrm{SOI}$ in hydrogen-fuelled engines using different nozzle configurations. They injected hydrogen at SOl of $140^{\circ} \mathrm{CA}, 80^{\circ} \mathrm{CA}, 40^{\circ} \mathrm{CA}$ BTDC with a centrally mounted single-hole injector (with a hole at an angle of $50^{\circ}$ with respect to the injector axis), a 6-hole injector, and a 13-hole injector; side-mounted 6-hole and 5-hole injectors were also employed. Depending on the injector design, they used an injection pressure of $80-116$ bar with a duration of $18.5-22^{\circ}$ CA. With single-hole injectors the $\mathrm{H}_{2}$ jet was not affected by the in-cylinder tumble motion. Therefore, it was concluded that the fuel distribution was dominated by the jet's momentum as redirected after wall impingement. For the 5-hole and 6-hole injectors, fast jet penetration and significant wall-jet interaction was observed for early injection. For the later SOI timings, slower jet penetration was noticed and the mixing process was not dominated by jet-wall interactions. Finally it was concluded that at late SOl timings all injector configurations were unfavorable, since the rich mixture remained within the squish zone (very close to the walls) due to insufficient time for the jet to emerge back towards the center of the combustion chamber. This was found to be a consequence of the jet interaction with the piston crown, thus optimizing the piston design could enhance the mixing characteristics in hydrogenfuelled engines.

Scarcelli et al [26] conducted experiments and computational simulations by Reynolds Averaged Navier Stokes (RANS) in order to study the effect of different SOI timings (140-20 ${ }^{\circ} \mathrm{CA}$ BTDC) and different orientations of a single-hole injector (with respect to the spark plug location) on the mixing and combustion characteristics of hydrogen-fuelled IC engines. It was noticed that a nozzle orientation towards the exhaust quenching zone with an early SOl timing would deliver the highest engine efficiency. This was found to be a consequence of the engine tumble motion that could redirect the rich mixture from the quenching zone towards the center of the cylinder and the spark plug. Additionally it was found that at very late SOI timings (SOI $\leq 40^{\circ} \mathrm{CA}$ BTDC) only an injector orientation towards the spark plug could provide high engine efficiency and combustion stability. Scarcelli et al [27] extended their studies on the effect of different nozzle designs (single-hole and 13-hole), injector orientations and injection pressures on mixture quality in a hydrogen engine at 1500 RPM under 1 bar intake pressure. It was found that with a centrally mounted single-hole injector (and with the nozzle pointing towards the exhaust side), combination of a relatively low injection pressure $\left(P_{0}=25\right.$ bar $)$ and a long injection duration $\left(74.5^{\circ} \mathrm{CA}\right)$ could result in a more desirable mixture at ignition timing when compared to a short injection $\left(17.5^{\circ} \mathrm{CA}\right)$ with high injection pressure $\left(P_{0}=100\right.$ bar). In particular, for the former strategy a more homogeneous mixture was noticed in the vicinity of the spark plug compared to the latter strategy.

Messner et al [28] used RANS modelling to study the mixture formation with a side mounted multi-hole injector and a SOI of $40^{\circ} \mathrm{CA}$ and $60^{\circ} \mathrm{CA}$ BTDC at 2000 RPM. They also used experiments at 1000 RPM to compare with simulations at the same conditions using a SOI of $120^{\circ} \mathrm{CA}$ BTDC. For the latter 
they observed that a fairly homogeneous mixture was formed throughout most of the combustion chamber at the time of ignition, but high local concentration existed under the injector side of the chamber.

Multiple-split injection strategies in DI gasoline engines, i.e. delivering the fuel in two or more injection pulses within a cycle, have been found to enhance engine efficiency and moreover to reduce tailpipe emissions [30-35]. It is believed that a multiple-injection strategy could also optimise hydrogen mixing with in-cylinder air. For instance, if the hydrogen injector has nozzle(s) pointing towards the spark plug, the last injection pulse could ensure the existence of 'sufficient' fuel in the vicinity of the spark plug at the time of ignition. However, studies on multiple injections in DI hydrogen engines are very limited in the literature. One of the authors of the current paper has conducted experimental studies on a double-pulse DI injection strategy for spark ignition (SI) and homogeneous charge compression ignition ( $\mathrm{HCCl})$ hydrogen engines [12, 35]. It was noticed that with a double-pulse injection strategy at full load, the flame was less distorted on a macro-scale than with a single-pulse injection strategy. However, it was not clear whether this was a flow-field effect from the momentum exchange between the hydrogen jets and the in-cylinder air or a fuel concentration effect.

\section{Hydrogen Combustion Modelling}

With reference to conventional IC engines, combustion can be categorized in two different modes, a non-premixed mode or diffusion flame combustion in diesel engines, and a premixed mode with propagation flame combustion in PFI SI gasoline engines. However, DISI engines with extensive fuel stratification extended the premixed mode to partially-premixed flame propagation. Concerning hydrogen-fuelled DISI engines, both premixed and partially-premixed combustion modes may exist depending on injection timing. Specifically, early injection can lead to pre-mixed flame propagation, whilst late injection to mixture stratification and partially-premixed combustion.

To computationally study the combustion stroke of an IC engine cycle the numerical code must simultaneously solve the flow equations and resolve the chemistry reactions. A detailed approach to account for chemistry is to couple the set of complex chemistry reactions with the computational fluid dynamics (CFD) solver [36-38]. This method can be computationally very expensive and normally requires a considerable amount of CPU time. The other approach is to substitute the actual chemical reactions by different types of theoretical relations mainly based on the 'flamelet' assumption [39]. For the latter, the chemical time-scale is considered short in comparison to that of convection and diffusion, hence, combustion is assumed to occur within asymptotically thin layers embedded in the domain [39, 40]. Various turbulent combustion modelling techniques have been developed based on the flamelet concept such as the coherent flame model (CFM) [41, 42], extended and modified CFM models [44, 45], and fractal flame model (FFM) [42]. In CFM the flame surface area is defined by a balance equation which describes the transport of the flame surface by the turbulent flow field and other physical mechanisms involved. However, the preliminary CFM formulation was just able to model premixed combustion. Therefore, the extended CFM (ECFM) model and other advanced versions of CFM have been developed to make the Page 3 of 21 model capable of solving combustion in highly stratified mixtures, i.e. partially-premixed combustion. The FFM model uses the concept of fractal geometry to account for wrinkling of the flame surface by the turbulence; moreover, it considers the flame strain imposed by the turbulent eddies [42]. With respect to combustion modelling in hydrogen engines, most previous studies have not considered resolving the full chemistry but, instead, they have used modelling techniques primarily based on the CFM model and the laminar flame concept [45-50]. A few computational studies have used detailed chemical reactions in hydrogen-fuelled $\mathrm{IC}$ engines but only for $\mathrm{HCCl}$ applications or diesel-type cycles [36-38, 51-55].

\section{Present Contribution}

Very few computational studies have been conducted on mixture formation and, particularly, combustion in hydrogenfuelled IC engines, using various injection strategies. Former computational work by the current authors using both RANS and Large Eddy Simulations (LES) [29] focused primarily on mixture formation in a boosted hydrogen-fuelled IC engine for different injection pressures and equivalence ratios. The present work aims to understand further the mixture formation in the same hydrogen engine geometry to that used in [29] but under low-load operation and with different injection strategies. Furthermore, the current work investigates the in-cylinder combustion process. The objectives of the work were set on the basis of RANS modelling and can be summarized as follows:

- Investigation of the effect of injection timing and injection pressure on in-cylinder mixture formation with a singlepulse injection strategy.

- Study of the effect of a double-pulse injection strategy on the mixture formation and hydrogen concentration at ignition timing.

- $\quad$ Study of the combustion process using a detailed complex chemistry reaction approach using single and doublepulse injection strategies.

\section{Computational Methodology}

\section{Modelling Approach}

Within the goals of the current work computational modelling was conducted by means of the STAR-CCM+ code [56]. The code support both coupled and segregated finite volume solvers. The coupled model solves the conservation equations for mass, momentum, and energy simultaneously using a pseudo-time-marching approach, whereas, the segregated model solves the flow equations in a sequential manner. In previous publications of the current authors the capability of the coupled solver was used and validated for high pressure hydrogen injection studies, including prediction of the nearnozzle shock structures $[57,58]$. The coupled configuration is desirable for modelling high-pressure hydrogen injection processes due to its relatively higher accuracy in resolving compressible flows; however, it requires a very small time-step for transient simulations that involve dynamic grids, especially for engine flows. Therefore, for the scope of the current work and the requirement to model the piston's motion and hydrogen injection, the segregated solver was employed. However, both solvers have been tested by the authors for 
hydrogen injection and mixing processes and satisfactory agreement has been observed between them on grids with resolution similar to that of the current paper.

In addition to the continuity equation, the Navier-Stokes equations and the energy equation, the code solves transport equations for each one of the species involved. For $N$ species, $N-1$ transport equations are solved; the mass fraction of the $N^{\text {th }}$ component is defined by the restriction that the total mass fraction must be unity [58].

The simulations conducted in the current work involved three main processes, hydrogen injection, hydrogen-air mixing, and combustion. Turbulence was modeled by means of a RANS turbulence model; in particular the two-equation SST $k-\omega$ model proposed by Menter [59] was used. This specific turbulence model was used because it has been shown to be able to resolve the characteristics of under-expanded rounded jets in a relatively accurate manner and also to avoid some compressibility related issues [60-61].

The combustion process was resolved by coupling the CFD solver to a detailed chemistry solver (DARS, Digital Analysis of Reactive Systems) [62]. DARS considered 19 reversible elementary kinetic reactions for hydrogen as presented in [53] (included in the appendix). Various detailed kinetics schemes for hydrogen oxidization have been suggested that often differ by the number of reactions and their rate constants [65-69]. The DARS detailed chemistry used in the current work was based on $\mathrm{H}_{2}-\mathrm{O}_{2}$ chemical reaction with nitrogen as the main bath gas.

The DARS solver used the operator splitting algorithm [68] in order to decouple the general species transport equation (equation 1) from the flow field equations and obtain a set of ordinary differential equations (ODEs). This algorithm considered different time scales for the chemical reactions and the flow field. To make sure that the flow field can be decoupled from the chemical reactions it is necessary to keep a low Courant number during the combustion process. This means that the use of a considerably small time-step is crucial. The time-step should be adjusted based on the general flow characteristics and the level of turbulence involved.

In the current study the formation of $\mathrm{NO}_{x}$ was not considered since it has been shown that for the equivalence ratio used, $\Phi=0.5$, the formation of $\mathrm{NO}_{x}$ is very small and can be neglected [21]. However, for richer mixtures, $\mathrm{NO}_{x}$ levels increase drastically and an extra chemistry model, such as the Zeldovich $\mathrm{NO}_{x}$ approach $[21,45,69]$ needs to be implemented into the detailed kinetic reactions of table 1.

The ignition energy provided by the spark plug was simulated by increasing the temperature in a spherical volume with radius of $r=1 \mathrm{~mm}$ at the location where the spark gap would exist and the spark plasma would be initiated. The spark duration was considered to be $10{ }^{\circ} \mathrm{CA}$. No other submodels were implemented to simulate the spark ignition process due to the broadly unknown processes and transient effects in the vicinity of the spark electrodes (including heat losses, etc.).

Page 4 of 21

\section{Simulation Setup}

The engine geometry in which the current computational work was performed on corresponds to one cylinder of a 4-cylinder 2-liter engine. The structure and characteristics of the incylinder flow for this engine have been studied extensively previously by means of optical experiments and CFD; e.g. see [70]. Table 1 summarizes some important geometrical and operational characteristics of the engine. For the current work, a special automated methodology was employed to account for piston and valve motion throughout the cycle while preserving the grid quality within acceptable thresholds. The details of the dynamic mesh methodology developed by the current authors can be found in reference [29]. First a CFD simulation was performed to study the gas-exchange phase, intake stroke and early compression stroke. Then the calculated flow field, state variables, and turbulence parameters were used to start the simulation for each injection strategy from the respective SOI. The simulations were conducted using second-order schemes for both temporal and spatial discretisation.

Table 1. Engine specifications and operating conditions.

\begin{tabular}{|l|l|}
\hline Engine Head & 4-valve Pentroof \\
\hline Piston Shape & Flat \\
\hline Bore $[\mathrm{mm}] \times$ Stroke $[\mathrm{mm}]$ & $82.5 \times 88.9$ \\
\hline Connecting Rod [mm] & 165.2 \\
\hline Injection System & DI Multi-Hole \\
\hline Compression Ratio & $9.8: 1$ \\
\hline Engine Speed [RPM] & 1000 \\
\hline Intake Pressure [bar] & 0.5 \\
\hline Valve Timings [ ${ }^{\circ} \mathrm{CA}$ ATDC] & IVO: 695, IVC: 235 \\
\hline Injection Timing [ ${ }^{\circ} \mathrm{CA}$ ATDC] & Single Pulse: 240,280 \\
\hline Injection Pressure [bar] & Double Pulse: 260 \& 310 \\
\hline Ignition Timing [ ${ }^{\circ} \mathrm{CA}$ ATDC] & 35,70 \\
\hline
\end{tabular}

In order to resolve the complex shapes of the engine geometry and the injector nozzles a hybrid grid was employed. Particularly, hexahedral cells were used to resolve the piston's swap volume whereas polyhedral cells were employed for the pent-roof volume and the injector nozzles. In total $500 \mathrm{~K}$ polyhedral elements and $1.1 \mathrm{M}$ hexahedral cells (at $235^{\circ} \mathrm{CA}$ ATDC) resolved the geometry and formed the discretized computational domain. Through the dynamic mesh methodology the polyhedral part of the grid remained fixed (since no valve motion occurred during the injection and combustion processes) and only the hexahedral grid of the swap volume was replaced at certain intervals. Figure 1 illustrates the engine geometry and the computational grid. It has been reported that, for the injection pressures used in the current work, choked conditions exist at the nozzle exit $(M a=1)$, followed by a shock-containing under-expanded jet after the nozzle exit [27, 29, 57-58]. Certain grid resolutions need to be employed near the nozzle exit and the nozzle volume in order to capture the sonic characteristics of such under-expanded jets [57]. However within the objectives of the current work a compromise was reached between the grid resolution and the computational cost. In particular, polyhedral cells with size of $0.02 \mathrm{~mm}$ were fitted inside the nozzle volume and the volume close to the nozzle exit. The cell size then gradually increased 
to a maximum size of $0.7 \mathrm{~mm}$. Further information on the near nozzle resolution is provided in a later section.

A multi-hole injector with stepped nozzle geometry was used for the present work. The injector had a 6-hole arrangement that consisted of two groups of 3 asymmetric holes and was mounted with a $45^{\circ}$ inclination on the intake side between the two intake valves as shown in Figure 1. According to previous experimental work with this injector and hydrogen fuelling [12, 22] it was decided to adopt the injector orientation with the two sets of plumes pointing upwards towards the pentroof. The orientation of each injector hole was set on the basis of angles measured from gasoline spray images acquired with this injector [71]. Building on previous computational work conducted for the stepped nozzles of this injector [29], it was assumed that the flow was choked at the inner hole of the stepped nozzle with diameter of $0.2 \mathrm{~mm}$.

In total four simulations of hydrogen injection/mixing and two simulations of combustion were conducted. Injection simulations included various combinations of two injection pressures, 35 and 70 bar and three injection strategies, specifically early injection soon after IVC with $\mathrm{SOI}=240^{\circ} \mathrm{CA}$ ATDC, double-pulse injection with $\mathrm{SOI}=260^{\circ}$ and $310^{\circ} \mathrm{CA}$ ATDC, as well as a later injection with $\mathrm{SOI}=280^{\circ} \mathrm{CA}$ ATDC. Injection durations of $56^{\circ} \mathrm{CA}$ and $28^{\circ} \mathrm{CA}$ were selected for injection pressures of $P_{0}=35$ bar and $P_{0}=70$ bar, respectively, in order to establish a global in-cylinder equivalence ratio of $\Phi=0.5$. All the test cases are summarized in table 2 .

It needs to be clarified here that these injection simulations were set up on the basis of previous experimental work by one of the co-author of this paper [12]. Specifically, that work employed a hydrogen engine of the same air volume capacity to that used in the current study, along with the side injector geometry that was selected for the simulations of the present work. According to those experiments, although the nominal injection pressure was $P_{0}=70$ bar, the injector required longer injection duration to deliver the expected theoretical amount of hydrogen for $\Phi=0.5$ (based on isentropic relations [72] and the assumption of chocked condition at the inner hole of the stepped injector). In particular, to match $\Phi=0.5$ with that longer duration, a value of $P_{0}=35$ bar was calculated as the mean 'effective' injection pressure. It is worth noting here that, $\mathrm{Yu}$ et al [73] conducted a series of experimental studies on underexpanded jets issued from a gaseous fuel injector and concluded that as a result of compressibility effects and injector losses the operative injection pressure could build up gradually and reach its nominal value after several ms from SOI. Therefore, in the current study two different injection pressures of constant 35 bar and 70 bar were compared for the same SOI of $280^{\circ}$ CA ATDC. The double-pulse injection SOls were also obtained from [12]. It is worth clarifying further that the boundary condition of fixed injection pressure used here essentially represented a constant rate of injection (ROI). The mass flow rate of a real injector normally has a ramped profile due to needle actuation delays. Scarcelli et al [27] investigated the effect of different arbitrary profiles of nozzle mass flow rate on the mixing process in DI hydrogen engines. It was shown that $\mathrm{ROI}$ can have a significant effect on the hydrogen jet and mixing characteristics. However, in the current work it was purposely decided to fix the injection pressure at two values of 70 bar and 35 bar to represent a constant rate and decouple any injector delay effects. This

Page 5 of 21 decision was based on the aforementioned work of [73] that demonstrated 'pressure building' effects during injection.

A time step of $0.1^{\circ} \mathrm{CA}$ was selected for the intake and compression strokes before the start of injection. For the hydrogen injection process, all simulations started with a time step of $0.01^{\circ} \mathrm{CA}$ and then the time step was gradually increased to $0.05^{\circ} \mathrm{CA}$. For the combustion stage, as discussed earlier, in order to assure decoupling of the operator splitting algorithm, the time step had to be reduced from $0.05^{\circ} \mathrm{CA}$ down to $0.01^{\circ} \mathrm{CA}$ again. Considering that wall heat transfer processes were not of direct interest to the objectives of the current work, an adiabatic no-slip condition was adopted at all walls. At the nozzle exits a stagnation condition was applied. The level of turbulence at the nozzle exits was defined on the basis of previous studies by the current authors on underexpanded hydrogen jets issued from circular nozzles [29, 59]. A total temperature of $T_{0}=300 \mathrm{~K}$ was adopted for the hydrogen gas upstream of the nozzle exit (i.e. stored in the fuel tank).

Table 2. Different test cases examined in the present study.

\begin{tabular}{|c|c|c|c|c|c|}
\hline $\begin{array}{c}\text { Test } \\
\text { case }\end{array}$ & $\begin{array}{c}\text { Injection } \\
\text { Pulse }\end{array}$ & $\begin{array}{c}\text { Injection } \\
\text { Pressure }[\text { bar] }\end{array}$ & $\begin{array}{c}\text { Injection } \\
\text { Duration }\left[{ }^{\circ} \mathrm{CA}\right]\end{array}$ & SOI [ $\left.{ }^{\circ} \mathrm{CA}\right]$ & $\begin{array}{c}\text { Ignition Timing } \\
{\left[{ }^{\circ} \mathrm{CA} \text { ATDC] }\right.}\end{array}$ \\
\hline 1 & Single & 70 & 28 & 240 & 345 \\
\hline 2 & Single & 70 & 28 & 280 & Not Ignited \\
\hline 3 & Double & 70 & 18,10 & 260,310 & 345 \\
\hline 4 & Single & 35 & 56 & 280 & Not Ignited \\
\hline
\end{tabular}

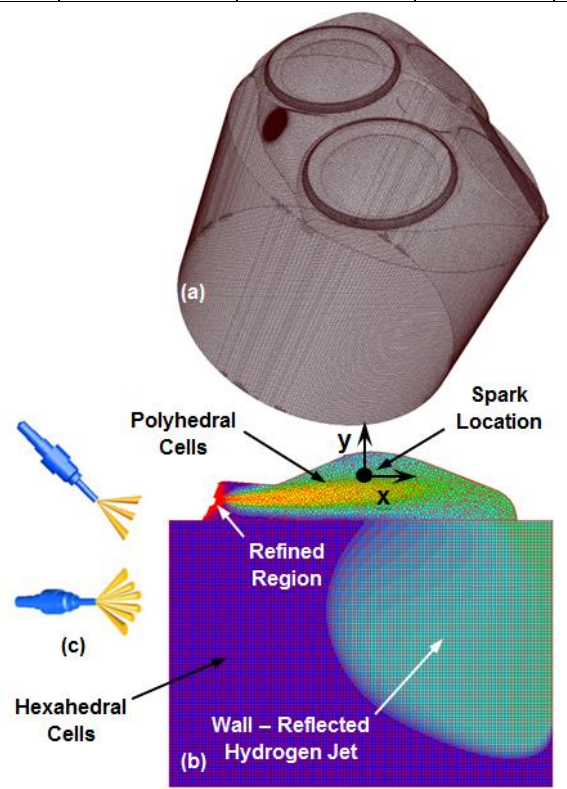

Figure 1. (a) Engine geometry, (b) Cross section of the hybrid grid on the vertical tumble plane, (c) Orientation of the multi-hole injector nozzles with the nominal fuel injection patterns.

\section{Validation}

A certain set of experimental data were available from optical diagnostics work at UCL's lab in the DISI engine under study here, as well as in a second optical DISI engine of same capacity to that used here, with the same injector to the one used here but with slightly different pentroof angle and lower 
compression ratio. Specifically, PIV data from the engine under study here were available for motoring conditions at 1500 RPM, low-load operation (0.5 bar inlet plenum pressure). These data have been presented in [70] and discussed with respect to CFD simulations using a coarser grid of $\sim 1$ million cells with $\mathrm{k}-\varepsilon$ and $\mathrm{k}-\varepsilon$ RNG turbulence models. That CFD study also used adiabatic walls but employed a methodology to account effects related to 'blowby' and heat losses, typical of optical engines. The second optical engine was also run at low load conditions of 0.5 bar, but at 1000 RPM in firing mode using side hydrogen injection via the injector nozzle geometry employed here (6 'stepped' holes) $[12,22]$. This work allowed quantification of the flame's growth and centroid motion via high-speed imaging, as well as heat release analysis from incylinder pressure records. This is the main reason why the simulations of the current study were at 1000 RPM, 0.5 bar.

In order to provide validation of the in-cylinder airflow predictions of the current methodology, a simulation test case was carried out at 1500 RPM, 0.5 bar inlet pressure to compare with the PIV data and CFD simulations of [70]. Adiabatic walls were used but no 'blowby' was modelled since the primary focus was on the intake stroke and up to intake valve closure. Figure 2 shows a comparison of the prediction of airflow motion on the current denser hexahedral grid (than of [70] at $230^{\circ} \mathrm{CA}$ ATDC, i.e. close to inlet valve closure, with the PIV data area marked by the red square. The velocity scales are the same for direct comparison and good agreement is observed. The reader may refer to [70] for comparison with the earlier denser grid and PIV data at other crank angles.

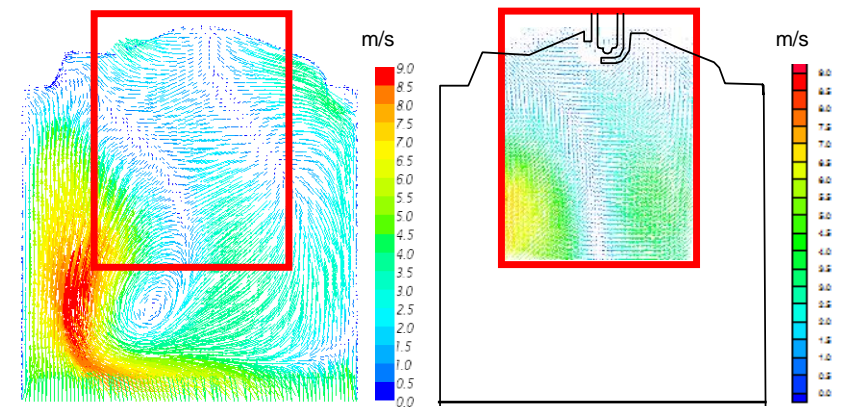

Figure 2. Comparison between the current RANS and PIV [70].

Simulations of the airflow were then repeated at 1000 RPM up to inlet valve closure. The results were used as initial condition for the hydrogen injection simulations, utilising also the denser polyhedral area of cells in the pentroof (described earlier). Grid dependency studies were also performed and before selecting the grid employed for the objectives of the current paper but the results are not elaborated on here for brevity [74].

Regarding combustion, validation of the flame growth predictions was only possible qualitatively by comparing with the flame imaging data obtained in the second optical engine at UCL that had been run with hydrogen at the conditions of the current study $[12,22]$. This is discussed further in the results section. It is also noted that further comparisons of the predictions of the present work are made with optical data and simulations from other DISI engines in the literature, namely [24, 25, 75]. However, these comparisons were only possible on a qualitative basis since the engine geometries, engine speeds, etc. have been different amongst different authors.

Page 6 of 21
Finally, it is noted that a large body of predictions of the hydrogen injection process has been recently published by the current authors where the effect of grid resolution was addressed for straight and stepped injector nozzles using RANS and LES [29]. Employing similar resolution to [29, 57] (of the order $0.01 \mathrm{~mm}$ in grid spacing inside the nozzle and at the nozzle exit) in order to examine the structure of the underexpanded hydrogen jets for all 6 nozzle holes, and their interaction, would mean that many tens of million cells would have to be used, which made the exercise impractical. Nevertheless, the grid density employed was sufficient to capture the existence of the Mach disk and supersonic jet characteristics behind it. Figure 3 shows the relevant characteristics of one of the 6 stepped nozzle holes of the injector under study. It is seen that the step restricts the Mach disk width in comparison to what would be expected for simple orifices, as has been discussed in detail on denser grid in [29, 57]. The reader is also guided to the recent publication of [27] where the near-nozzle resolution was similar to that of the current study and where comparisons between RANS and visualisation of the hydrogen injection process and mixture formation by schlieren and planar laser induced fluorescence demonstrated good agreement.

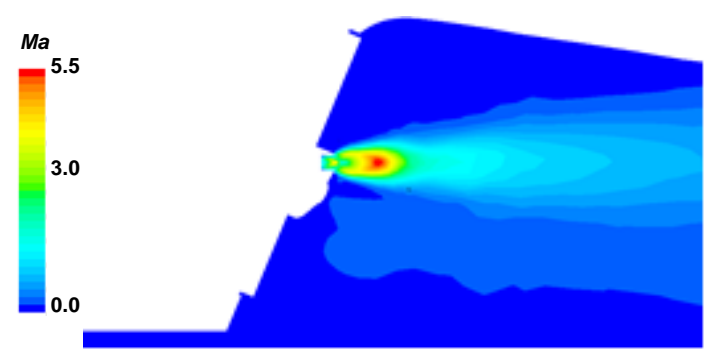

Figure 3. Mach contours near a nozzle hole of the multi-hole injector.

\section{Results and Discussion}

\section{In-Cylinder Mixture Formation}

Comparisons between spatial mole fraction $(\boldsymbol{x})$ of hydrogen for the different test cases of table 2 are presented in figures 4 and 5 . It is clear that retarding the injection timing resulted in relatively lower penetration of the injected hydrogen jets in figure 4 . This is due to the existence of a higher in-cylinder pressure during the late injection timings which reduced the nozzle pressure ratio (ratio of the nozzle upstream total pressure to the cylinder static pressure) and consequently decreased the jet penetration [76]. In particular, as shown in figure 4 , on the vertical tumble plane at $1^{\circ} \mathrm{CA}$ ASOI the case with $P_{0}=70$ bar and $\mathrm{SOI}=240^{\circ} \mathrm{CA}$ ATDC showed a higher jet penetration by about $15 \%$ and $30 \%$ in comparison to the cases with same injection pressure but with SOI of $260^{\circ} \mathrm{CA}$ and $280^{\circ}$ CA ATDC, respectively. Furthermore, it is also clear that for the single-injection cases with $\mathrm{SOI}=280^{\circ} \mathrm{CA}$ ATDC, the lower injection pressure of $P_{0}=35$ bar resulted in a lower jet penetration by about $20 \%$ than that of $P_{0}=70$ bar. Figure 4 also shows that after $1^{\circ} \mathrm{CA}$ and $2^{\circ} \mathrm{CA}$ ASOl for the two jets with $P_{0}=70$ bar and 35 bar, respectively, the issuing jets seem to 'adhere' to the convex surface of the engine's pentroof head. This has been attributed to the Coanda effect by [77]. This effect can potentially enhance the mixing process by increasing the entrainment rate of the in-cylinder air [77]. 

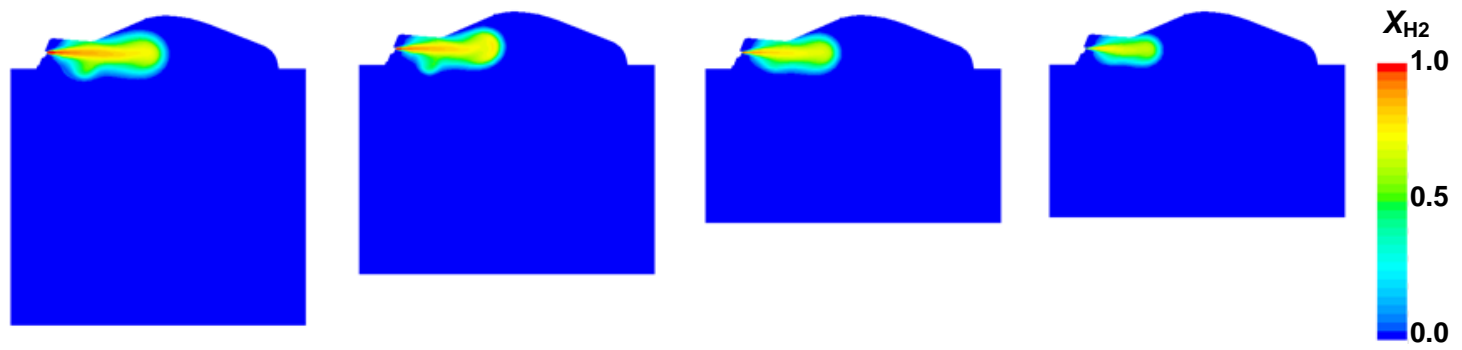

$2^{\circ} \mathrm{CA}$
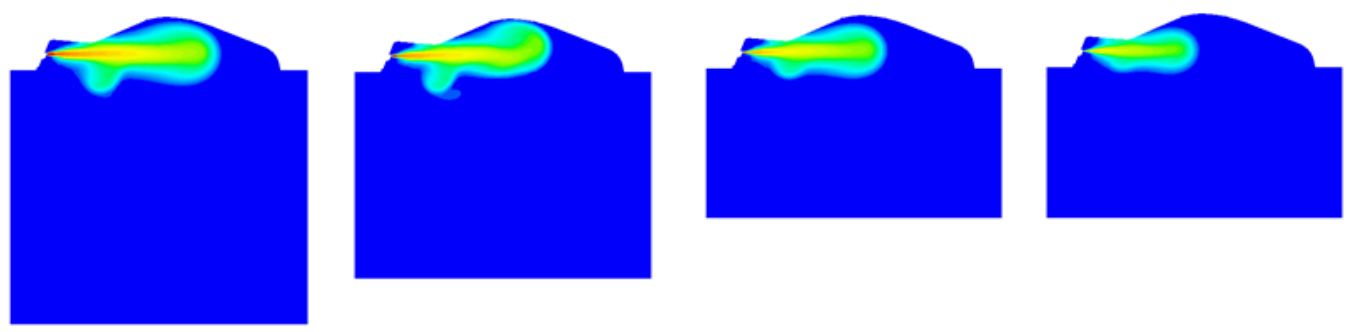

$3^{\circ} \mathrm{CA}$

ASOI
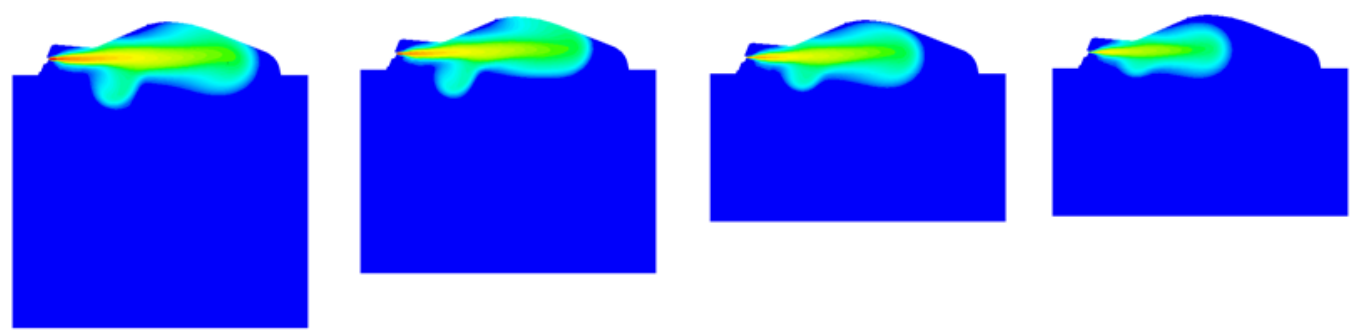

$4^{\circ} \mathrm{CA}$

ASOI
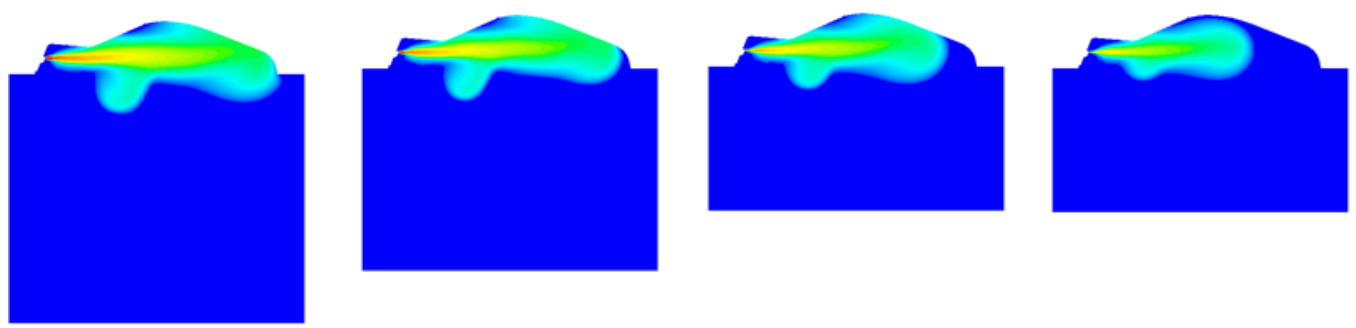

$5^{\circ} \mathrm{CA}$
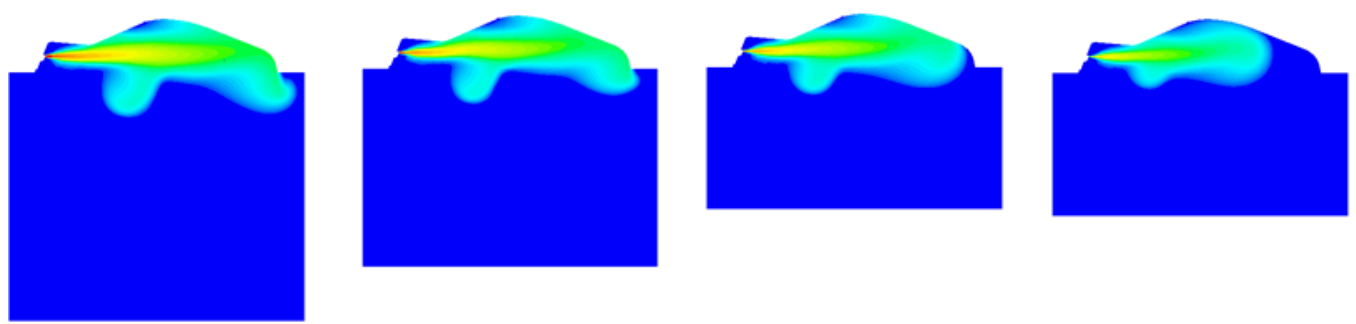

$P_{0}=70$ bar

Single Pulse SOI $=240^{\circ} \mathrm{CA}$ ATDC

$P_{0}=70$ bar

Double Pulse SOI $=260^{\circ} \mathrm{CA}$ ATDC
$P_{0}=70$ bar

Single Pulse SOI $=280^{\circ} \mathrm{CA}$ ATDC
$P_{0}=35$ bar

Single Pulse

SOI $=280^{\circ} \mathrm{CA}$ ATDC

Figure 4. Mole fraction $(\boldsymbol{X})$ of hydrogen on the vertical tumble plane for different crank angles ASOI. 


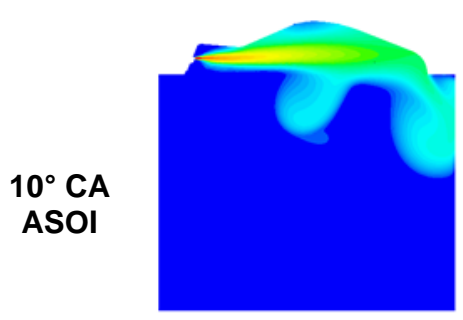

$250^{\circ} \mathrm{CA}$ ATDC

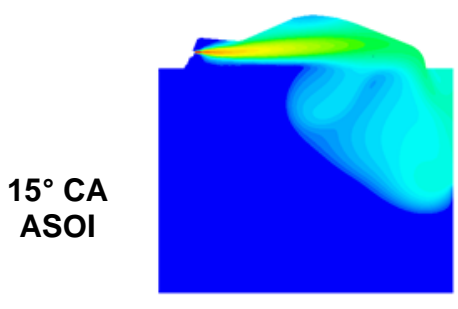

$255^{\circ} \mathrm{CA}$ ATDC

$20^{\circ} \mathrm{CA}$

ASOI

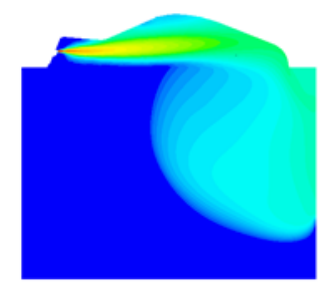

$260^{\circ}$ CA ATDC
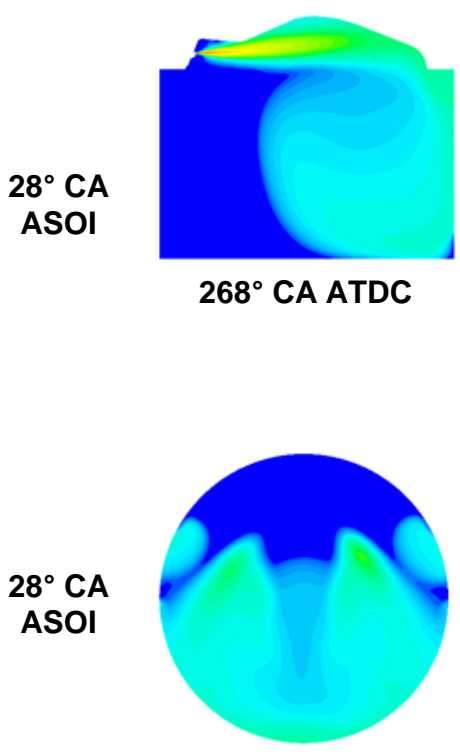

$P_{0}=70$ bar

Single Pulse SOI $=240^{\circ}$ CA ATDC

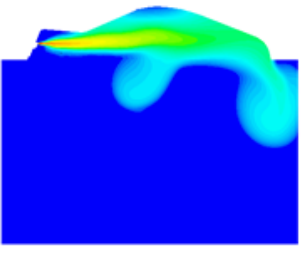

$270^{\circ}$ CA ATDC

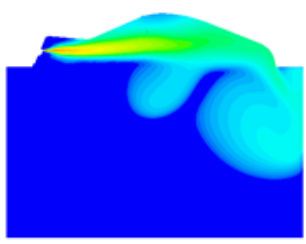

$275^{\circ}$ CA ATDC
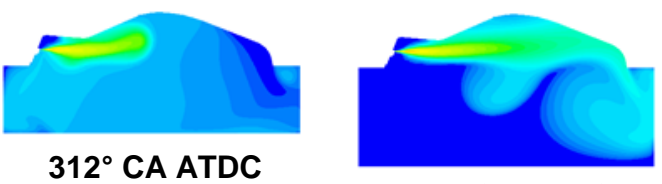

$300^{\circ} \mathrm{CA}$ ATDC

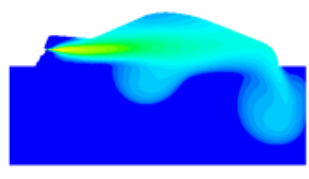

$300^{\circ} \mathrm{CA}$ ATDC
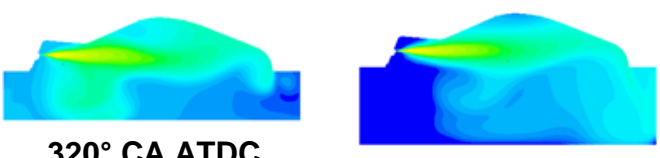

$308^{\circ} \mathrm{CA}$ ATDC
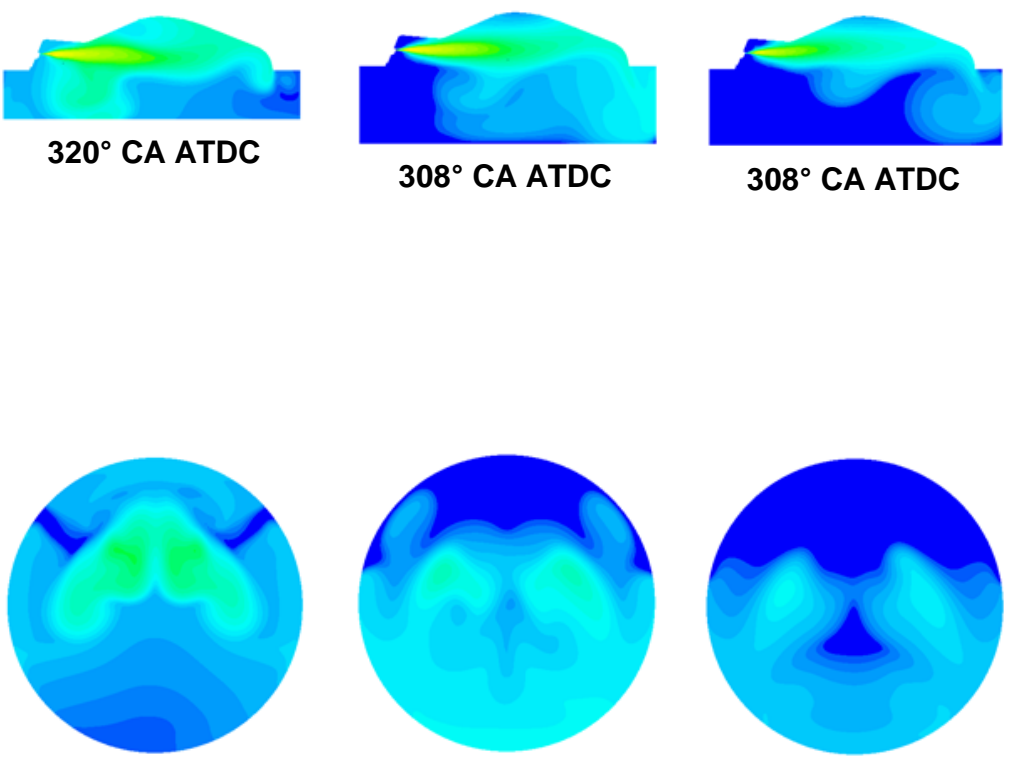

$P_{0}=70$ bar

Double Pulse SOI $=260^{\circ}$ CA ATDC
Single Pulse SOI $=280^{\circ} \mathrm{CA}$ ATDC
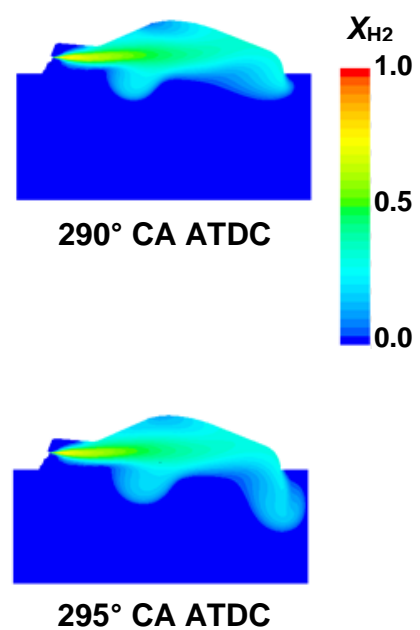

$295^{\circ}$ CA ATDC

Figure 5. Mole fraction $(\boldsymbol{X})$ of hydrogen on the vertical tumble and horizontal (10 $\mathrm{mm}$ below the fire face) planes.

Page 8 of 21 
The mixing process up to the end of injection (EOI) is presented in figure 5 . It should be reminded that for the case with $P_{0}=35$ bar, the injection duration was $56^{\circ} \mathrm{CA}$. It was found that for SOI $=240^{\circ} \mathrm{CA}$ ATDC the in-cylinder hydrogen cloud started forming a 'tumble-like' motion from around $15^{\circ} \mathrm{CA}$ ASOI. At EOI, hydrogen was mixed with air over about two thirds of the chamber's volume. At this point the majority of the mixture had a hydrogen mole fraction in the range $0.25-0.3$.

For the double-pulse strategy it was found that for the first pulse, from about $18^{\circ} \mathrm{CA}$ ASOI, the in-cylinder hydrogen cloud started exhibiting a tumble-like motion similar to that mentioned for the single-pulse case with SOI $=240^{\circ}$ CA ATDC. However, due to the lower jet penetration and shorter injection pulse, this tumble motion was relatively weaker. It is also observed that at the beginning of the second injection pulse, the hydrogen delivered by the first pulse has already mixed with almost all the air inside the chamber and its mole fraction ranged between 0.2-0.3. It was also found that the tumble motion created by the first pulse fanned out the hydrogen from the exhaust to the intake side of the chamber. The second pulse produced a relatively inhomogeneous final mixture when compared to the mixture at EOI produced by the single pulse early injection strategy of $\mathrm{SOI}=240^{\circ} \mathrm{CA}$ ATDC.

For the injection strategy with $\mathrm{SOI}=280^{\circ} \mathrm{CA}$ ATDC and $P_{0}=70$ bar it was found that the hydrogen cloud did not produce a complete tumble and the motion was distorted after impinging on the piston crown. This can potentially halt the hydrogen circulation from the exhaust side towards the intake side and leave a large amount of hydrogen in the vicinity of the exhaust quenching zone. However, due to the smaller engine volume at EOI of this injection strategy (when compared to the early injection strategy with $\mathrm{SOI}=240^{\circ} \mathrm{CA}$ ATDC), hydrogen seems to have propagated further towards the intake side.

For the case of $\mathrm{SOI}=280^{\circ} \mathrm{CA}$ ATDC with $P_{0}=35$ bar it was observed that within $28^{\circ} \mathrm{CA}$ ASOI, the hydrogen cloud that had reflected off the liner started to impinge onto the piston crown. At this time a relatively weak circulation region was formed under the exhaust side. The injection duration for this case was $56^{\circ} \mathrm{CA}$ and the effect is investigated in more detail later in the paper.

The effect of the different injection strategies on the in-cylinder pressure is presented in figure 6 (no combustion modelled). This figure also contains the simulated motoring engine pressure without fuelling for direct comparison. It was found that the hydrogen injection process increased the in-cylinder pressure well over that of the motoring conditions without injection. Specifically, a higher peak in-cylinder pressure was observed than motoring by $27.5 \%, 23.2 \%, 22.0 \%$, and $19.5 \%$ for the cases with $\mathrm{SOI}=240^{\circ} \mathrm{CA}$ ATDC, double-pulse injection, $\mathrm{SOI}=280^{\circ} \mathrm{CA}$ ATDC with $P_{0}=70$ bar, and SOI $=280^{\circ} \mathrm{CA}$ ATDC with $P_{0}=35$ bar, respectively. A similar pattern to that in figure 4 has also been observed experimentally by our group [12, 35]. This pressure rise is not due to the high pressure of the injection process; the hydrogen jet at such high pressures is expanded through a big normal shock forming a Mach disk and its pressure reaches the in-cylinder pressure after a very tiny distance (3-5 nozzle diameters) from the nozzle exit [57]. It is simply a thermodynamic effect of the large hydrogen mass added to the system. According to Dalton's law for gaseous mixtures, the pressure of a mixture of gases is equal to the sum of the partial pressures of the individual mixture species. Applying Dalton's law to the ideal gas equation of state showed that the pressure of the in-cylinder mixture with injection should theoretically be $\sim 1.2$ times greater than that of the non-injected engine motoring condition. However, different strategies showed a different rise and peak of the in-cylinder pressure. This was the effect of the different SOI timings applied. Specifically, the calculated $20 \%$ rise in pressure referred to a mixture that contained the total amount of the injected hydrogen whilst in practice the hydrogen was gradually added to the chamber from different SOI timings.

The earlier the SOI, the earlier the deviation of the in-cylinder pressure from that of engine motoring. This can be seen clearly in figure 6 . In particular, the fastest and slowest rise in pressure were for the cases with $\mathrm{SOI}=240^{\circ} \mathrm{CA}$ and $\mathrm{SOI}=280^{\circ}$ CA ATDC, respectively. However, slightly lower pressure rise was noticed for the case with $P_{0}=35$ bar than the case with $P_{0}=70$ for similar SOI. This was because the total amount of hydrogen was introduced into the cylinder faster for the case of $P_{0}=70$ bar and the remaining upward motion of the piston past EOI led to higher peak in-cylinder pressure at TDC. The simulated peak pressure during motoring was $\sim 10.1$ bar. This value is in agreement with thermodynamic compression calculations using simply the ratio of specific heats of hydrogen/air. However, it is about $15 \%$ higher than the peak pressure measured at motoring conditions in an optical engine of identical configuration in UCL's lab [70]. This was expected because of the relevant heat transfer and 'blowby' processes purposely not modelled here to enable focus on differences related solely to the injection process. However, this is currently under study and will be reported in a future publication. It is also noted that pressure measurements at UCL in an optical engine of similar capacity to that employed here [12] have shown very similar differences between motoring and hydrogen DI fuelling in-cylinder pressure traces.

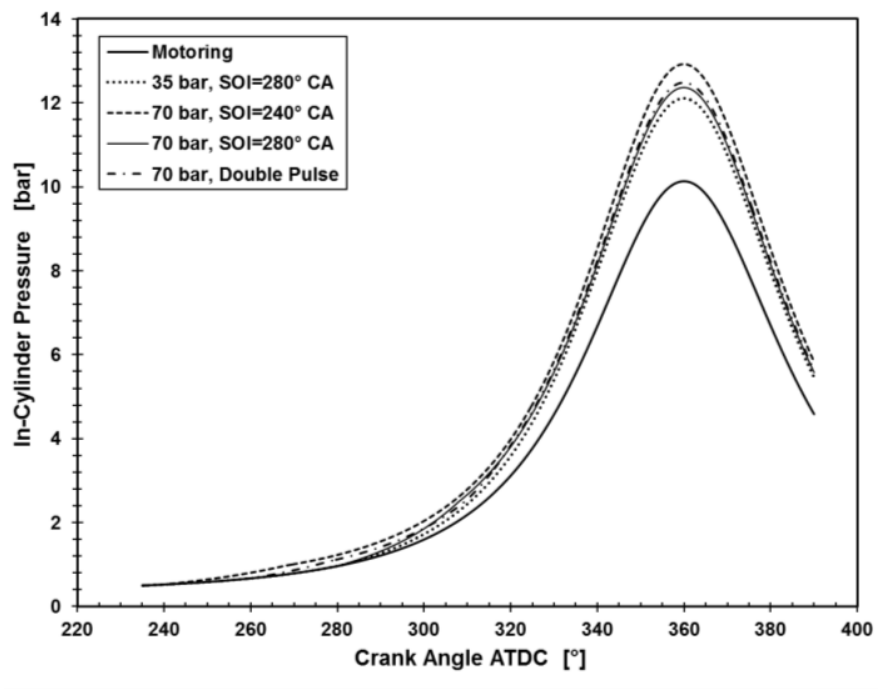

Figure 6. Effect of different injection strategies on the in-cylinder pressure trace.

The spatial variation of equivalence ratio $\Phi$ and also the velocity vectors at ignition timing are illustrated in figures 7 and 8; these contours refer to the vertical central tumble plane in figure 7 and to a horizontal plane $4.2 \mathrm{~mm}$ above the engine fire face $(5.8 \mathrm{~mm}$ below the spark location), respectively. For 
$\mathrm{SOI}=240^{\circ} \mathrm{CA}$ ATDC it was noticed that a relatively homogeneous mixture was produced. The equivalence ratio ranged from $\Phi=0.4$ to $\Phi=0.55$, with the majority of the domain being at an equivalence ratio very close to the global value of $\Phi=0.5$. The highest value of $\Phi$ was located on the intake side within the quenching zone. This clearly shows that the tumble motion, produced by the impinging hydrogen 'cloud' (see figure 5 ), distributed the hydrogen gas relatively homogeneously throughout the combustion chamber.

Further quantitative comparisons are presented in Figure 9. This figure shows the distribution of equivalence ratio on a horizontal line running through the spark location from inlet to exhaust. With the early injection strategy of $\mathrm{SOI}=240^{\circ} \mathrm{CA}$ ATDC, the equivalence ratio around the spark plug was $\Phi=0.51$, very close to its global value.

In their experimental work, Kaiser and White [24] reported formation of a 'quiet' homogeneous mixture for early injection strategies with a 6-hole side-mounted injector, similar to what was observed in the present work. They used an injection duration of $50^{\circ} \mathrm{CA}$ for both their 'intermediate' strategy with
$\mathrm{SOI}=270^{\circ} \mathrm{CA}$ ATDC and 'late' one with SOI $=282.5^{\circ} \mathrm{CA}$ ATDC. At ignition timing, the richest mixture was located under the injector on the intake side of the engine. Similarly, in the present study, for the early injection strategy with $\mathrm{SOI}=240^{\circ} \mathrm{CA}$ ATDC and relatively longer injection duration than [24] $\left(56^{\circ}\right.$ $\mathrm{CA})$, it was noticed that although a quiet homogeneous mixture was also formed, the highest equivalence ratio at the ignition timing was located under the intake side (injector side) of the combustion chamber. This is also in a satisfactory agreement with the computational and experimental work of Messner et al [28]. Using a side mounted multi-hole injector with an early injection strategy $\left(\mathrm{SOI}=240^{\circ} \mathrm{CA}\right.$ ATDC) with $20^{\circ} \mathrm{CA}$ duration, Messner et al [28] observed a fairly homogeneous mixture throughout the combustion chamber at the time of ignition. Interestingly, Messner et al [28] also noticed that the highest concentration for the early injection strategy was located under the injector side of the chamber at the ignition timing (see figure 7). The strong tumble motion induced by the high momentum hydrogen jets is believed to play an important role in the location of the rich mixture zones. In fact this significant motion fans out the hydrogen cloud from the exhaust side of the chamber towards the intake side.

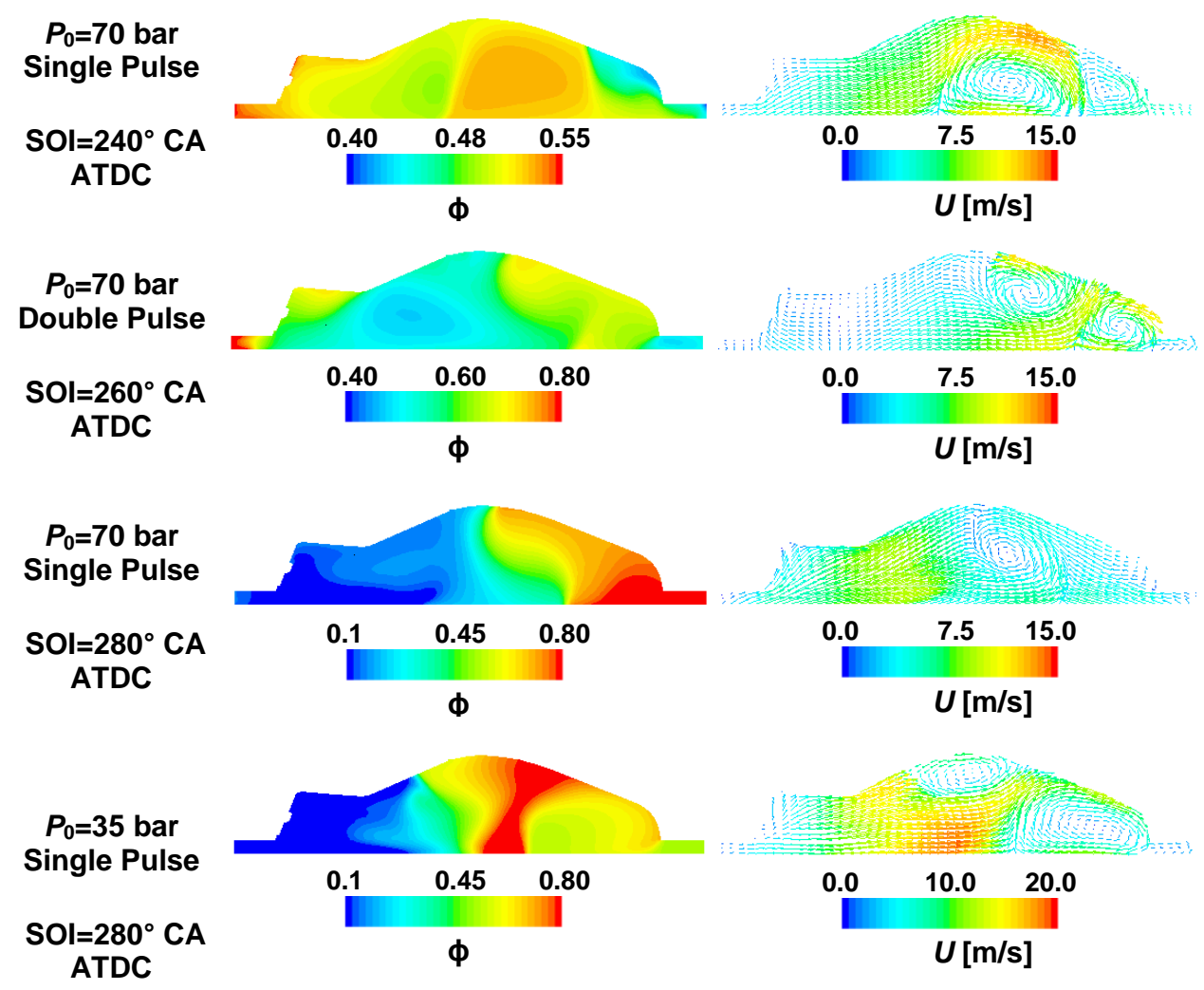

Figure 7. Distribution of equivalence ratio $(\Phi)$ and velocity vector field on the vertical tumble plane at ignition timing

Page 10 of 21 

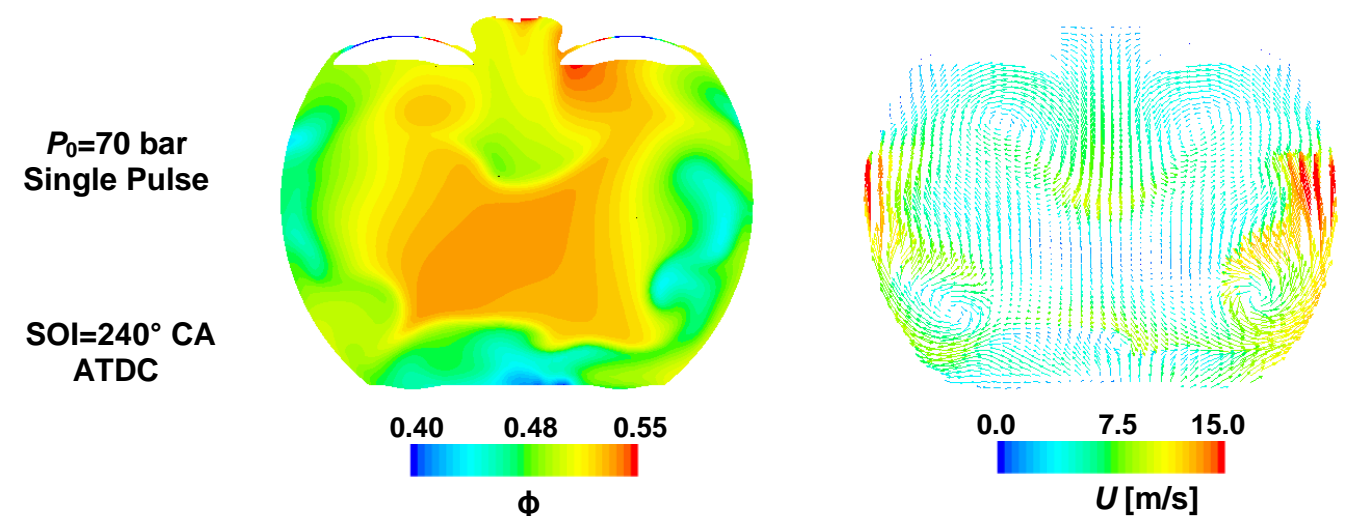

\section{$P_{0}=70$ bar Double Pulse \\ SOI $=260^{\circ} \mathrm{CA}$
ATDC}

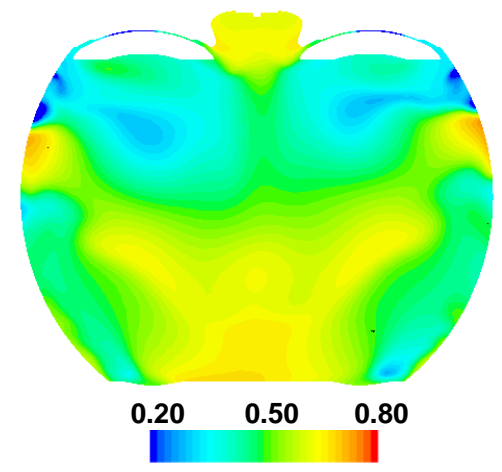

$\phi$

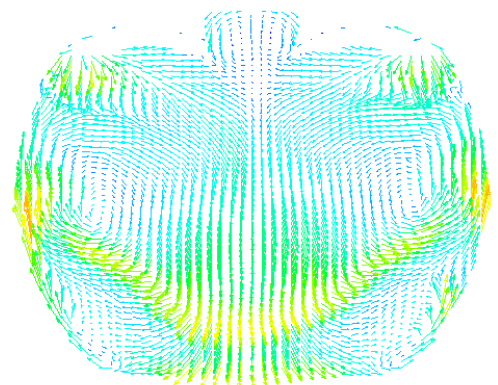

\section{$P_{0}=70$ bar Single Pulse \\ $\mathrm{SOI}=280^{\circ} \mathrm{CA}$ ATDC}
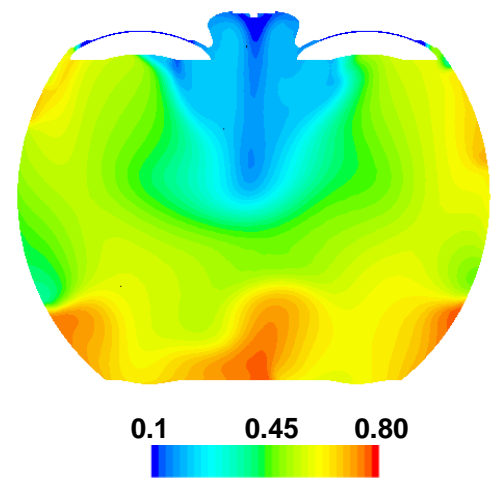

$\Phi$
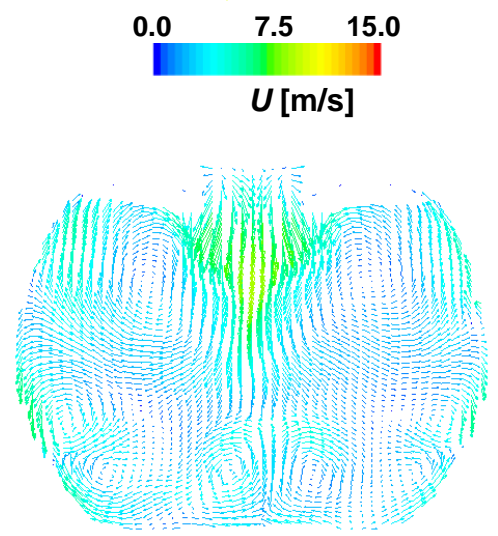

$P_{0}=35$ bar Single Pulse

\section{$\mathrm{SO}=280^{\circ} \mathrm{CA}$ ATDC}
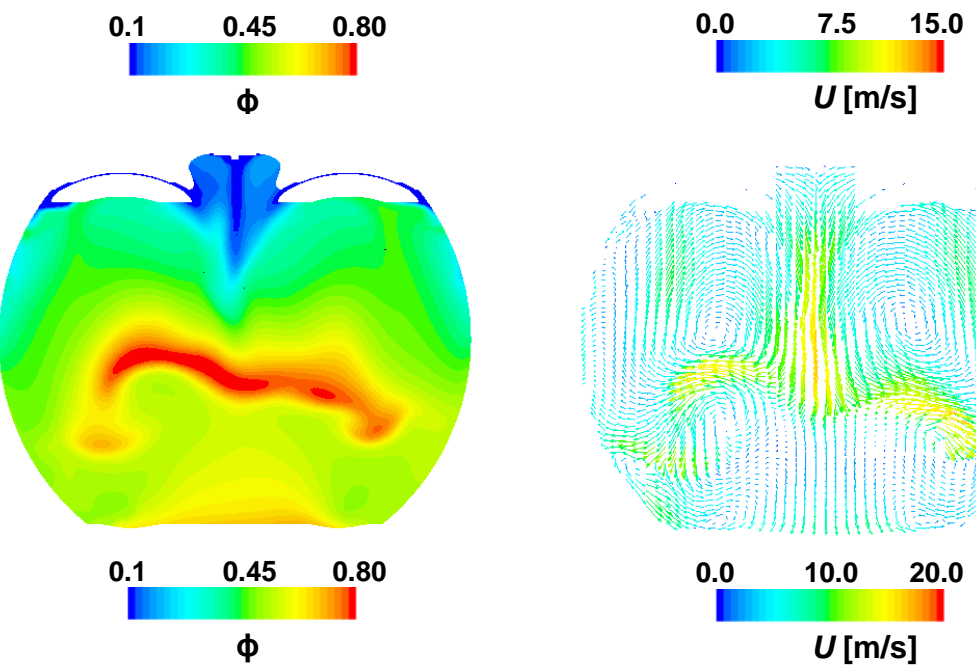

Figure 8. Distribution of equivalence ratio $(\Phi)$ and velocity vector field on horizontal plane $(4.2 \mathrm{~mm}$ above the fire face $)$ at ignition timing. 
For the double-pulse injection strategy it was found that at igniting timing, within the majority of the intake side area of the chamber, the equivalence ratio was in the range $\Phi=0.47-0.55$. However, the highest value of $\Phi$ was located within the intake quenching zone and was $\Phi=0.80$. This is believed to be a result of the interaction between the tumble motion induced by the first injection pulse which fanned out the jets issued by the second pulse towards the intake side. The majority of the exhaust side of the engine was at an equivalence ratio within $\Phi=0.5-0.7$. As shown in figure 9, the double injection strategy, led to an equivalence ratio at the spark plug location that was very close to that of the early single injection strategy with $\mathrm{SOI}=240^{\circ} \mathrm{CA}$ ATDC.

For the injection strategy with $\mathrm{SOI}=280^{\circ} \mathrm{CA}$ ATDC and injection pressure $\mathrm{P} 0=70$ bar, significant mixture stratification was observed at ignition timing in figures 5 and 6 . The equivalence ratio on the exhaust side of the engine ranged from $\Phi=0.65$ to $\Phi=0.84$, with the highest value of $\Phi$ residing within the exhaust quenching zone. In contrast, the equivalence ratio of the intake side of the chamber ranged from $\Phi=0.3$ to values as low as $\Phi=0.01$. The equivalence ratio at the spark plug location was $\Phi=0.28$ as shown in figure 9 . The highly stratified mixture produced by this injection strategy is believed to be an effect of the distortion of the tumble motion of the hydrogen cloud after impinging on the piston crown. This inhibited hydrogen motion towards the intake side; instead the hydrogen cloud was pushed by the piston and squeezed.

A high level of mixture stratification was also noticed for the injection strategy with the same SOI of $280^{\circ} \mathrm{CA}$ ATDC but with $\mathrm{P} 0=35$ bar in figures 5 and 6 . For $\mathrm{P} 0=35$ bar, the exhaust side of the chamber had significantly higher equivalence ratio than the intake side before ignition timing, similar to that shown at ignition timing for $\mathrm{P} 0=70$ bar in figure 7 . However, due to the longer injection duration with $\mathrm{P} 0=35$ bar $\left(56^{\circ} \mathrm{CA}\right.$ in comparison to $28^{\circ} \mathrm{CA}$ for 70 bar), the rich mixture on the exhaust quenching zone gradually moved out and returned towards the center of the chamber. Consequently an equivalence ratio of $\Phi=0.5$ formed in the exhaust quenching zone. The highest value, $\Phi=0.95$, was located close to the center of the chamber in the vicinity of the piston crown. Figure 9 also demonstrates that with $\mathrm{SOI}=280^{\circ} \mathrm{CA}$ ATDC and $\mathrm{P} 0=35$ bar, an equivalence ratio of $\Phi=0.64$ was present in the vicinity of the spark location (associated with the longer duration of this strategy). Salazar and Kaiser [25], using side-mounted multi-hole hydrogen injectors with $\mathrm{SOI}=280^{\circ} \mathrm{CA}$ ATDC and injection pressure of $\mathrm{P} 0=80-116$ bar, reported very similar mixture characteristics to the injection strategies with $\mathrm{SOI}=280^{\circ} \mathrm{CA}$ ATDC of the current work. In fact for $\mathrm{SOI}=280^{\circ} \mathrm{CA}$ ATDC they examined five different configurations of multi-hole injectors and concluded that unfavorable mixtures were produced by all those injectors. Similar to the current study, Salazar and Kaiser [25] noted that for single pulse intermediate SOI, the downward jet momentum, interacted with the piston crown and spread the hydrogen jet into the squish zone, as there was no sufficient time to penetrate towards the center of the chamber.

Figures 7 and 8 also show the velocity vectors on the same vertical and horizontal planes to those used for the equivalence ratio contours. For the case of single injection with $\mathrm{SOI}=240^{\circ}$ CA ATDC, the double-pulse injection, and the single injection with $\mathrm{SOI}=280^{\circ} \mathrm{CA}$ ATDC with $\mathrm{PO}=35$ bar, two vortices can be seen on the vertical plane. In contrast, for the strategy with
$\mathrm{SOI}=280^{\circ} \mathrm{CA} \mathrm{ATDC}$ and $\mathrm{P} 0=70$ bar, only one vortex has formed.

For the injection with $\mathrm{SOI}=240^{\circ} \mathrm{CA}$ ATDC, interaction between the returning tumble (formed by the main part of the hydrogen jet) and the in-cylinder mixture in the quenching zone air, is believed to be the main cause of formation of the two vortices. For the double injection, the 'tumble-like' motion induced by the first pulse and the incoming motion from the second injection pulse, are also leading to double in-cylinder vortices. However, on this occasion the main central vortex is counter-rotating from exhaust to inlet (possibly forced into that direction by the piston's late motion and restricted in-cylinder volume). For the injection strategy with $P_{0}=35$ bar, $56^{\circ} \mathrm{CA}$ duration and $\mathrm{SOI}=280^{\circ} \mathrm{CA}$ ATDC, the central vortex is also counter-rotating; this can be due to the interaction of the returning flow formed by the early stages of injection with the flow formed in the center of the chamber during the final stages of injection. However, for the injection with $\mathrm{SOI}=280^{\circ} \mathrm{CA}$ ATDC and $P_{0}=70$ bar, the $28^{\circ} \mathrm{CA}$ injection duration and the short time available up to ignition led to a single vortex; this vortex is also counterrotating from exhaust to inlet. For the injection strategies with the two vortices, one of the vortices was typically located on the exhaust side close to the quenching zone. The location of the center for the second vortex though was different amongst strategies with more notable the occurrence of this in the vicinity of the spark location for $P_{0}=35$ bar.

The location and potential control of the second vortex may have a noticeable impact on the combustion characteristics and flame propagation pattern after ignition. As shown in figures 5 and 6 for both vertical and horizontal planes, the maximum velocity magnitude was typically $15 \mathrm{~m} / \mathrm{s}$ for all cases except for the strategy with $P_{0}=35$ bar and SOI $=280^{\circ}$ CA ATDC where a maximum velocity magnitude of $20 \mathrm{~m} / \mathrm{s}$ was predicted. This is believed to be related to the longer injection duration and closer EOI to ignition timing than the other strategies. The velocity field on the horizontal plane was more complex than the field shown on the vertical plane. At least four vortices can be seen on the horizontal plane for all cases. A comparison between the snapshots of equivalence ratio and velocity vectors in figures 5 and 6 reveals that the hydrogen distribution inside the chamber is governed by the velocity field characteristics. A correlation can be observed between the mixture stratification and the gradient of the velocity magnitude throughout the chamber.

It is also worth mentioning here that on the horizontal plane shown in figure 8 , the velocity field and equivalence ratio are almost symmetric about the $x$ axis (see figure 1). However a level of asymmetry can also be identified that is believed to be due to small differences in the velocity magnitude calculated for the under-expanded regions of the six nozzles. In particular, a small variation (even less than $1 \%$ ) in the grid resolution can easily trigger the asymmetry. However in a real injector due to several challenging factors including different surface roughness of the nozzle holes, not precisely identical nozzle diameters, etc. even higher levels of velocity variation and asymmetry can be expected. For instance in the experimental optical study conducted by Kaiser and White [24] a considerably high degree of asymmetry was noticed in the flow field after the hydrogen injection event. 

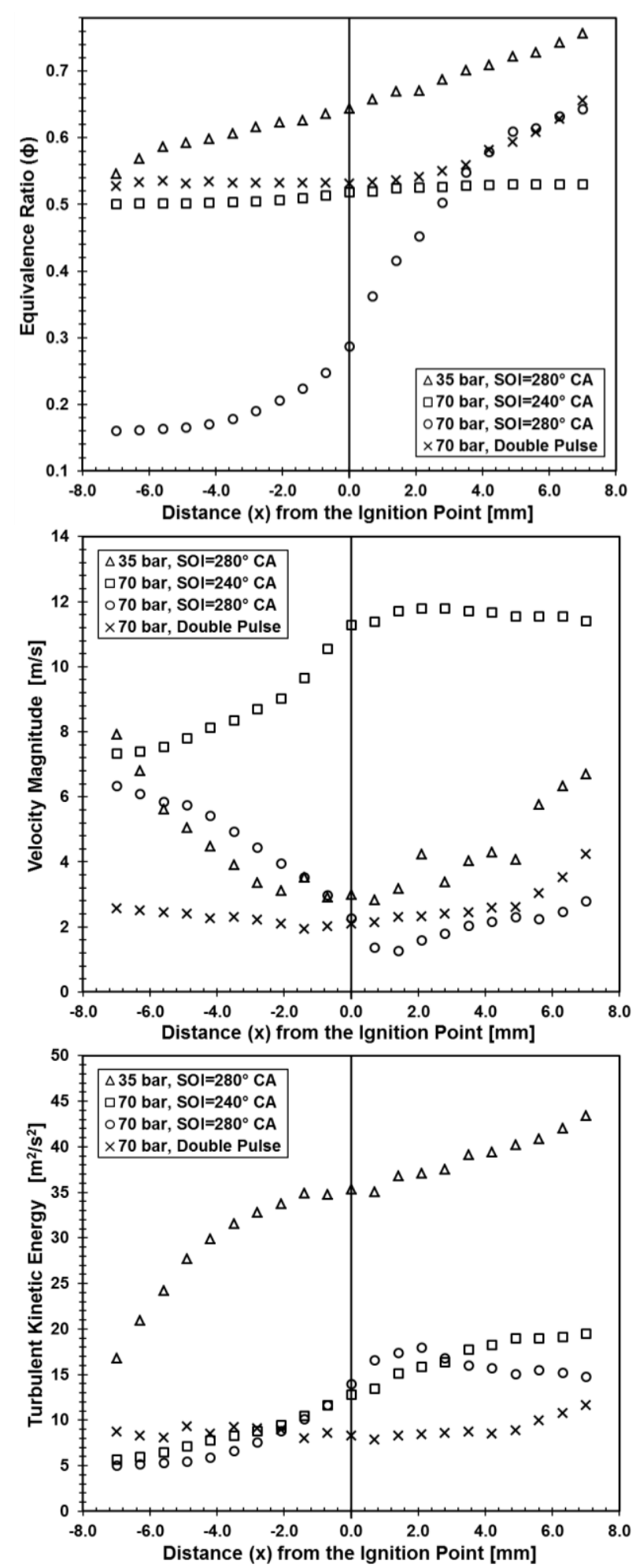

Figure 9. Equivalence ratio $(\Phi)$, velocity magnitude $(U)$ and turbulent kinetic energy in the vicinity of the spark location at ignition timing $(x-$ axis).
In addition to equivalence ratio, figure 9 shows the variation of the velocity magnitude and turbulent kinetic energy (TKE) on the same horizontal line running from inlet to exhaust and passing through the spark plug location. It can be seen that the early injection strategy with $\mathrm{SOI}=240^{\circ} \mathrm{CA}$ ATDC produced the highest velocity magnitude, $U=11.2 \mathrm{~m} / \mathrm{s}$, at the location of the spark plug. However, the other injection strategies produced relatively lower velocities at the same location $(U=2-3.5 \mathrm{~m} / \mathrm{s})$. This again is related to the effect of the returning tumble motion that was not produced in full by the other strategies. With respect to TKE, figure 9 shows that the injection strategy with $\mathrm{SOI}=280^{\circ} \mathrm{CA}$ ATDC and long injection duration $\left(P_{0}=35\right.$ bar) produced the highest value of TKE $=35 \mathrm{~m}^{2} / \mathrm{s}^{2}$. The lowest TKE among the injection strategies is associated with the double-pulse strategy. It can be said that long injection duration close to ignition timing would increase the turbulence level around the spark plug. Higher levels of turbulence would enhance the propagation rate of the flame throughout the chamber and could be used to optimize the combustion efficiency even for leaner mixtures. For the double injection strategy, although the EOI of the second pulse was relatively close to ignition timing $\left(320^{\circ} \mathrm{CA}\right.$ ATDC compared to $336^{\circ} \mathrm{CA}$ ATDC for $\mathrm{SOI}=280^{\circ} \mathrm{CA}$ ATDC and $P_{0}=35$ bar), the small duration of the second pulse $\left(10^{\circ} \mathrm{CA}\right)$ was not sufficient to form and maintain a high level of turbulence at ignition timing. The higher TKE in the vicinity of the spark location for the early injection strategy compared to the double-pulse strategy suggests that the relatively greater velocity magnitude of the tumble motion induced by the long early injection could as well enhance the level of turbulence.

Similar to figure 9 , the spatial variation of the velocity magnitude, velocity component in the horizontal, i.e. $\mathrm{x}$, direction $\left(U_{x}\right)$, and turbulent kinetic energy (TKE) are presented in figure 10 but over a vertical line running from the spark plug location to the piston crown (y direction in figure 1). Figure 10 essentially illustrates the profile of those quantities. The early injection strategy with $\mathrm{SOI}=240^{\circ} \mathrm{CA}$ ATDC shows again the highest velocity magnitude in the vicinity of the spark plug with $U \approx 12 \mathrm{~m} / \mathrm{s}$ at about $2 \mathrm{~mm}$ below the spark location. For the other strategies, the minimum velocity magnitude occurred in the vicinity of the spark plug whilst the maximum velocity occurred close to the center of the combustion chamber. The double-pulse injection, as well as the injection with $\mathrm{SOI}=280^{\circ}$ CA ATDC and $P_{0}=70$ bar, showed very similar trends in the velocity profile in figure 10 . A relatively sharper gradient was noticed for the injection strategy with $\mathrm{SOI}=280^{\circ} \mathrm{CA}$ ATDC and $P_{0}=35$ bar; the highest velocity magnitude of $U \approx 18 \mathrm{~ms}$ was found at $\sim 7 \mathrm{~mm}$ below the spark location.

The profile of the velocity component in the $x$ direction, $U_{x}$, shows in figure 10 that all strategies with $P_{0}=70$ bar exhibited positive values. For $P_{0}=35$ bar, from about $1 \mathrm{~mm}$ above the spark location the velocity component $\left(U_{x}\right)$ started accelerating in the negative direction. This can have a significant effect on flame propagation. Similar to figure 9, the TKE plot of figure 10 shows a noticeably higher level of turbulence in the vicinity of the spark location for the injection strategy with $P_{0}=35$ bar and $\mathrm{SOI}=280^{\circ} \mathrm{CA}$ ATDC in comparison to the other strategies. Specifically, this is $\sim 250 \%$ larger than the double-pulse strategy and $\sim 135 \%$ larger than the strategies with $P_{0}=70$ bar and $\mathrm{SOI}=240^{\circ} \mathrm{CA}$ ATDC or $\mathrm{SOI}=280^{\circ} \mathrm{CA}$ ATDC. 

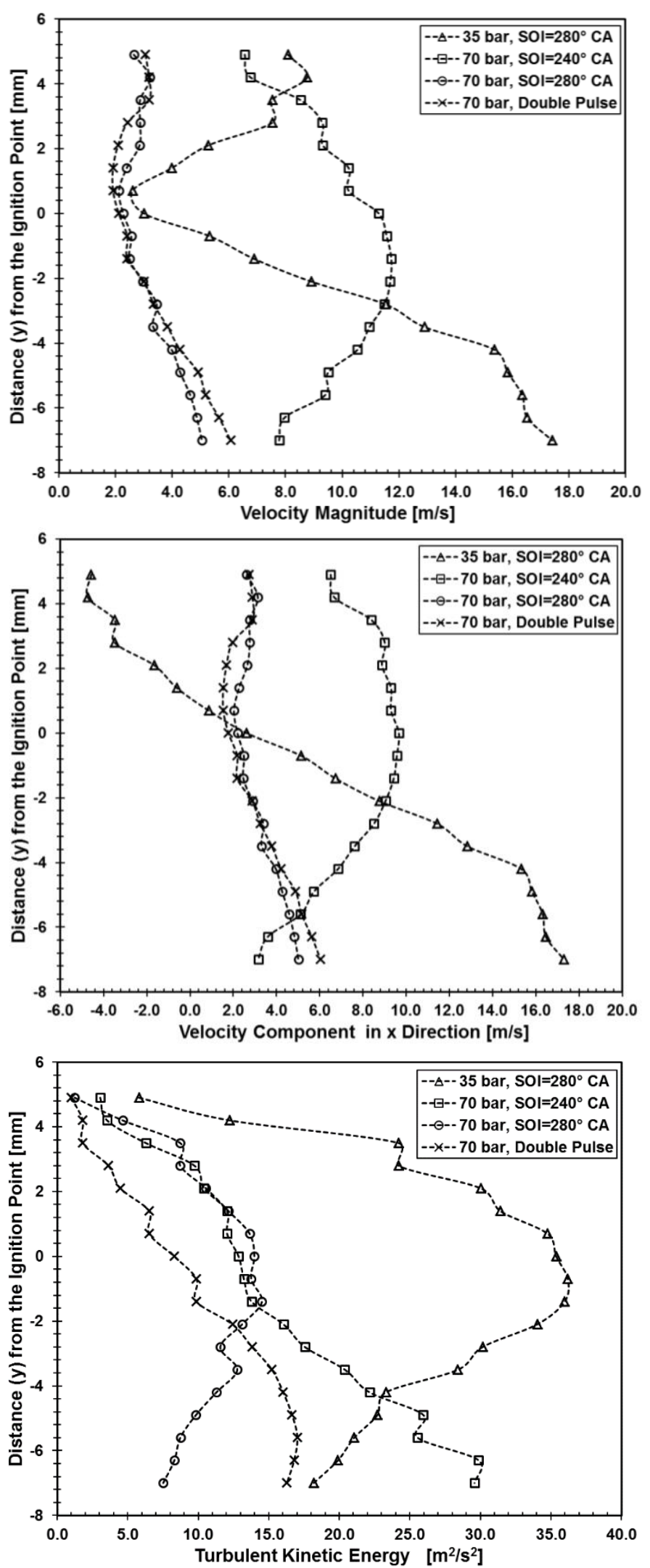

Figure 10 . Velocity magnitude $(U)$, velocity component in $x$ direction $\left(U_{x}\right)$ and turbulent kinetic energy in the vicinity of the spark location at ignition timing ( $y$-axis).
Based on the results of this section, it may be concluded that the early injection strategy with $\mathrm{SOI}=240^{\circ} \mathrm{CA}$ ATDC is the ideal option for homogeneous mixture distribution at ignition timing. However, it produced low levels of turbulence at the spark location, unlike the injection with the longest injection duration $\left(P_{0}=35\right.$ bar, $\mathrm{SOI}=280^{\circ} \mathrm{CA}$ ATDC) that produce the highest TKE. In contrast, the long injection strategy led to an equivalence ratio of about $\Phi=0.60-\Phi=0.75$ at the location of the spark plug at the ignition timing. This could increase the $\mathrm{NO}_{x}$ emissions. An ideal injection strategy should produce a relatively homogeneous mixture with high level of turbulence at the spark location at the ignition timing. This can be carried out using a double pulse strategy. The early pulse would produce a relatively homogeneous mixture at the beginning of the second pules. The later pulse must be fairly short in order to avoid producing a great degree of stratification; however it must be close enough to the ignition timing so as to maintain a high level of turbulence at the time of ignition. For instance, in order to maintain a global $\Phi=0.50$ with $P_{0}=70$ bar, an ideal injection strategy could be a double-pulse injection process with total duration of $28^{\circ} \mathrm{CA}$, split in a first injection pulse of $22^{\circ} \mathrm{CA}$ duration at about $\mathrm{SOI}=240^{\circ} \mathrm{CA}$ ATDC that would create a relatively homogeneous mixture with $\Phi \approx 0.4$ just before the beginning of a second pulse with $\mathrm{SOI}=334^{\circ} \mathrm{CA}$ ATDC and $6^{\circ} \mathrm{CA}$ duration. The second pulse then could produce a mixture with $\Phi=0.50$ and with appropriate level of turbulence at the vicinity of the spark plug. Obviously, further work is needed for more detailed analysis and optimization.

\section{Combustion Modelling}

In order to study the effect of injection strategy on combustion two combustion simulations were conducted in the current study, as detailed earlier. In particular, the mixture of the single pulse strategy with $\mathrm{SOI}=240^{\circ} \mathrm{CA}$ ATDC (56 $\mathrm{CA}$ duration), as well as that of the double-pulse strategy with $\mathrm{SOI}=260^{\circ} \mathrm{CA}$ ATDC (duration $18{ }^{\circ} \mathrm{CA}$ ) and $\mathrm{SOI}=310^{\circ} \mathrm{CA}$ ATDC (duration $10^{\circ} \mathrm{CA}$ ) were ignited at $345^{\circ} \mathrm{CA}$ ATDC (i.e. $15^{\circ} \mathrm{CA}$ spark advance). The pattern of flame growth at different CA degrees after ignition timing (AIT) is presented in figure 11 on the vertical tumble plane and in figure 12 on two horizontal planes ( 4.2 and $10 \mathrm{~mm}$ above the engine's fire face, or $5.8 \mathrm{~mm}$ below the spark location and at the spark location, respectively). Those contours are based on the mole fraction $X$ of hydrogen; the area with $X_{\mathrm{H} 2}=0.0$ demonstrates the burned gas, i.e. the shape of the enflamed area.

It was observed that for both injection strategies after $1^{\circ} \mathrm{CA}$ the flame started penetrating towards the exhaust side of the chamber with noticeably higher rate compared to that on the intake side. At first instance it might be explained as a result of higher equivalence ratio on the exhaust side, particularly for the double-pulse injection. However, it is noted that the singlepulse strategy showed even greater penetration rate towards the exhaust side despite the fact that this case had a more homogeneous mixture than the double-pulse strategy. 


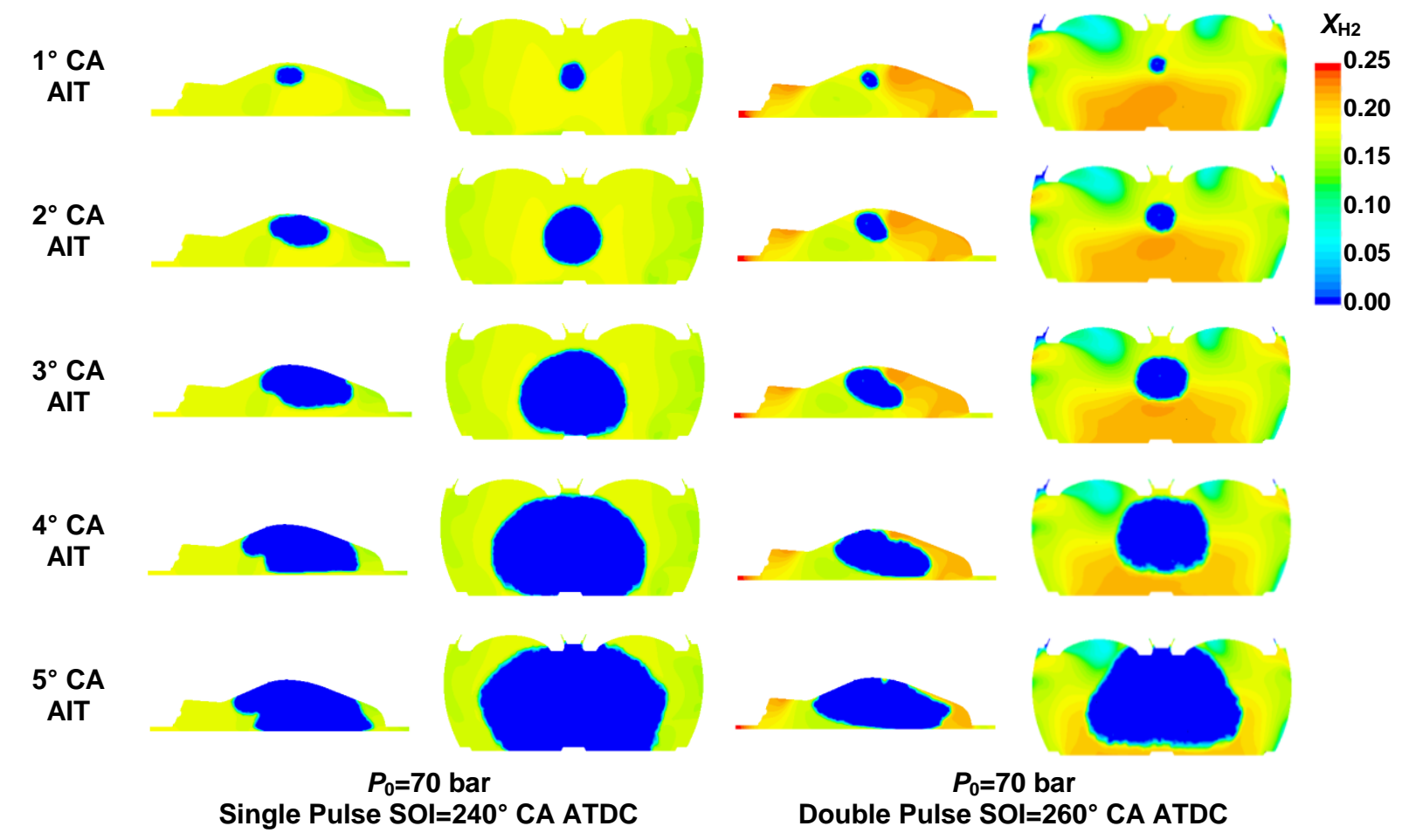

Figure 11. Flame growth at different CA degrees AIT on the vertical tumble and horizontal (10 mm above the fire face) planes.

$3^{\circ} \mathrm{CA}$

AIT
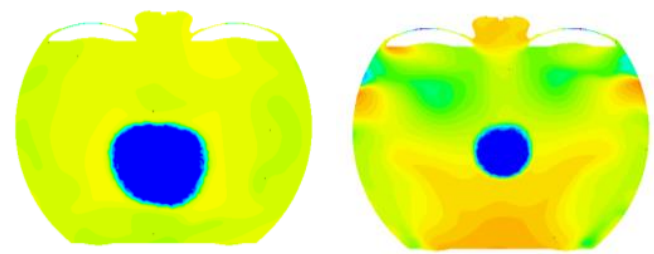

$4^{\circ} \mathrm{CA}$

AIT
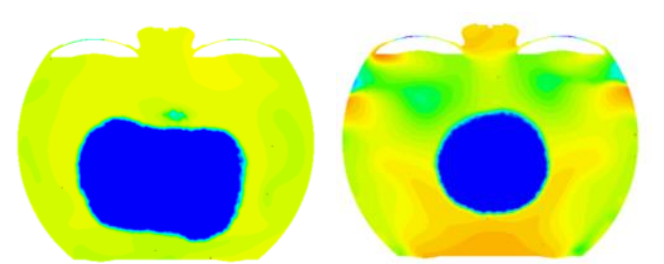

$X_{\mathrm{H} 2}$

$-0.25$

0.20

0.15

0.10

0.05

0.00

$5^{\circ} \mathrm{CA}$

AIT
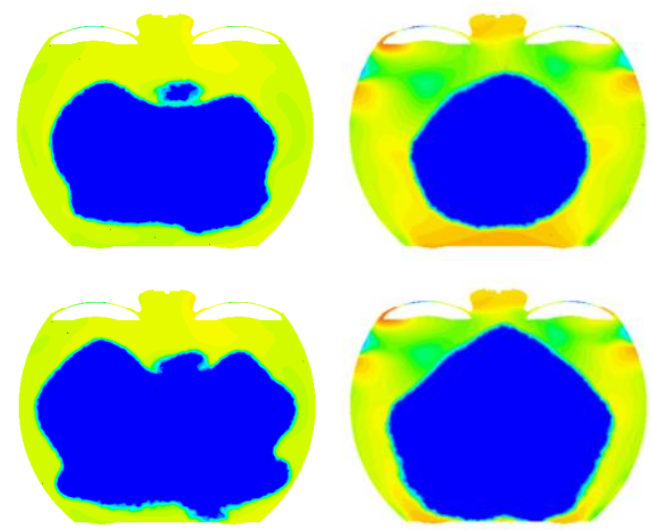

$P_{0}=70$ bar, Single

SOI $=240^{\circ}$ CA ATDC

$P_{0}=70$ bar, Double SOI $=260^{\circ}$ CA ATDC

Figure 12. Flame growth at different CA degrees AIT on horizontal plane (4.2 $\mathrm{mm}$ above fire face).
In order to investigate the cause of the aforementioned flame characteristic, the difference in laminar burning velocities between the two cases was evaluated using the pressure and temperature at ignition timing. Laminar burning velocities are typically presented in the literature as follows:

$$
S=S_{0}\left(\frac{T}{T_{0}}\right)^{\beta_{1}}\left(\frac{P}{P_{0}}\right)^{\beta_{2}}
$$

where the subscript ' 0 ' denotes reference conditions and parameters $\beta_{1}$ and $\beta_{2}$ depend on the equivalence ratio. Various values for the reference parameters of equation 5 have been suggested by several researchers for several fuels. Specifically for hydrogen there are only limited data at realistic in-cylinder conditions of temperature and pressure; the studies of [75] at $365 \mathrm{~K}$ from 1-10 bar and of [78] at conditions of up to 80 bar and $950 \mathrm{~K}$ are noted here. Considering that the pressure at ignition timing in the current study was about 10 bar and the temperature about 660-695 K, using the correlations suggested by [78] the double injection strategy was associated with about $6 \%$ lower laminar burning velocity than the single injection strategy. Therefore, it can be concluded that the differences in the velocity profile in the vicinity of the spark location played a more important role in the growth rate and direction of flame propagation than the local fuel concentration differences did. In particular, as shown in figures 7 and 8 , the velocity magnitude for the single-pulse strategy was $\sim 4$ times higher than that of the double injection. However, from the profile of the velocity component in the $x$ direction in figure 10 it is clear that for both injection strategies the direction of velocity was always towards the exhaust side. Additionally, noticeably higher flame growth rate is seen in figures 11 and 12 for the single-pulse injection in comparison to the double-pulse strategy. 
For direct quantitative comparison of the flame growth process for the two cases, an 'equivalent flame radius' was defined. This followed practices used in experimental studies and corresponded to the radius of a sphere with identical volume to that of the 3D flame shape. The development of this equivalent radius in time, as well as its rate of growth (i.e. equivalent flame speed) is presented in figure 13. This figure shows clearly that the flame radius and flame speed was consistently higher for the single-pulse strategy than for the double-pulse. However, for both strategies a peak maximum flame speed of $26-27 \mathrm{~m} / \mathrm{s}$ can be observed. This maximum velocity is in very good agreement with the maximum growth speed of about 25 $\mathrm{m} / \mathrm{s}$ measured in an optical engine of same capacity and running conditions to that of the current engine geometry and at $\Phi=0.5$ [22]. The maximum velocity in figure 13 occurs at about $2^{\circ} \mathrm{CA}$ AIT and $4^{\circ} \mathrm{CA}$ AIT for the single-pulse and double-pulse injection strategy, respectively. According to figure 9 it was at these crank angles that the flames started to interact with the wall of the combustion chamber, and/or piston crown; this may well be the reason behind the flame's deceleration after those timings.

The higher equivalent flame speed of the single-pulse strategy resulted in faster mass fraction burnt at specific timings than the double-pules strategy. Specifically, after $6^{\circ} \mathrm{CA}$ AIT it was found that $42 \%$ of the hydrogen mass had been burned for the single injection strategy and only $33 \%$ had been burned for the double-pulse strategy. Although at ignition timing both strategies had very similar in-cylinder pressures (within about $0.3 \mathrm{bar}$ ), after $6^{\circ} \mathrm{CA}$ AIT the in-cylinder pressure had increased to 21.5 bar and 19.2 bar for the single and double-pulse strategy, respectively, i.e. a difference of about $12 \%$.

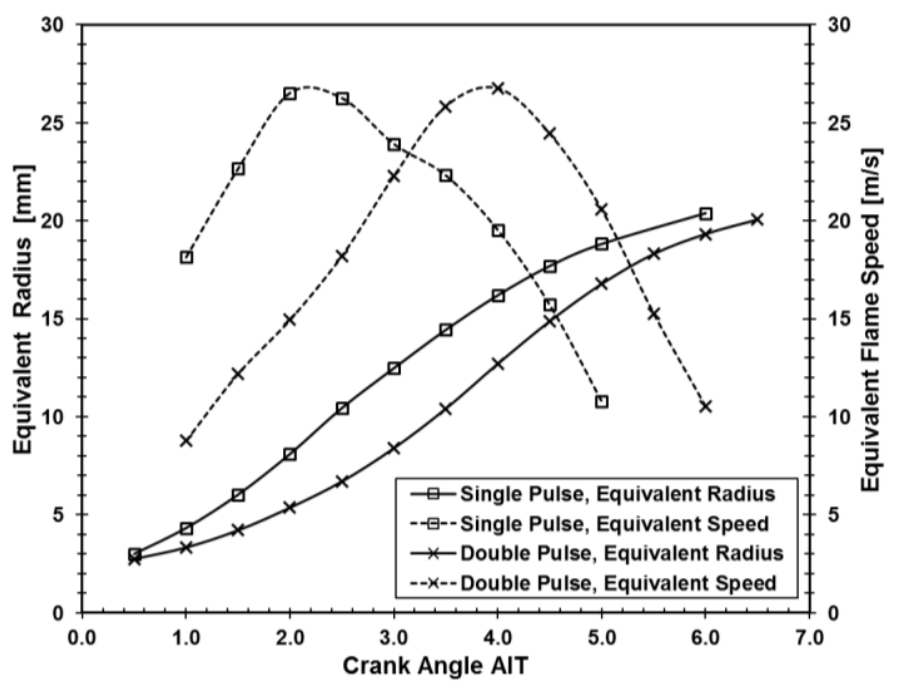

Figure 13. Equivalent flame radius and flame growth speed as function of CA degree AIT.

\section{Summary and Conclusions}

The present computational study investigated the mechanism of mixture formation and combustion in a hydrogen-fuelled engine under different injection strategies. Initially, the incylinder flow field predictions prior to injection timing were Page 16 of 21 validated against PIV data from an identical optical engine and good agreement was noted. The grid resolution for the injection event was selected by consultation of previous CFD work on under-expanded hydrogen jets by the current author and it was optimized to offer a balance in terms of computational cost. Two different injection timings, an early injection with $\mathrm{SOI}=240^{\circ} \mathrm{CA}$ ATDC (just after intake valve closure) and a retarded injection with $\mathrm{SOI}=280^{\circ} \mathrm{CA}$ ATDC were compared with 70 bar injection pressure. In addition, a strategy with $\mathrm{SOI}=280^{\circ} \mathrm{CA}$ ATDC an injection pressure of 35 bar was investigated. Finally a double-pulse injection was employed, using $\mathrm{SOI}=260^{\circ} \mathrm{CA}$ ATDC ( $18^{\circ} \mathrm{CA}$ duration) and $\mathrm{SOI}=310^{\circ} \mathrm{CA}$ ATDC $\left(10^{\circ} \mathrm{CA}\right.$ duration). The studies were conducted in a pentroof engine with a 6-hole side injector running at 1000 RPM and with a global equivalence ratio of $\Phi=0.50$. After evaluating the in-cylinder mixing phenomena, the combustion events of the single early injection strategy and of the double-pulse injection strategy were studied by detailed chemistry computations. The main conclusions of this work can be summarized as follows:

- The early injection strategy with $\mathrm{SOI}=240^{\circ} \mathrm{CA}$ ATDC and 70 bar produced relatively homogeneous mixture at ignition timing. This was the effect of a 'tumble-like' incylinder motion that was induced by the hydrogen jets from the early stages of injection. However, with the same injection pressure but by using a later SOI of $280^{\circ} \mathrm{CA}$ ATDC, a mixture of relatively high degree of stratification was formed at ignition timing. For this case it was clear that the typical in-cylinder tumble motion of the pentroof geometry was eliminated by the hydrogen jetting process and the jet itself did not have enough time to recreate a tumble-like motion as the earlier injection strategy did. Therefore, the fuel was not distributed over the domain in full but it was forced by the piston on the exhaust side of the engine.

- The flow field in the vicinity of the spark location was found to be highly dependent to the injection strategy. The early injection had the highest velocity magnitude in the spark area with $U \approx 12 \mathrm{~m} / \mathrm{s}$.

- The highest level of turbulent kinetic energy was predicted for the injection strategy with $\mathrm{SOI}=280^{\circ} \mathrm{CA}$ ATDC and injection pressure 35 bar. This is believed to be the effect of the relatively long injection duration of this strategy $\left(56^{\circ}\right.$ $\mathrm{CA}$ compared to $28^{\circ} \mathrm{CA}$ for the other strategies) which led to an EOl very close to the ignition timing of $345^{\circ} \mathrm{CA}$.

- For a global $\Phi=0.50$ with $P_{0}=70$ bar, an optimum injection strategy might be a double injection process with total duration of $28^{\circ} \mathrm{CA}$, split in a first injection pulse at about $\mathrm{SOI}=240^{\circ} \mathrm{CA}$ ATDC with of $22^{\circ} \mathrm{CA}$ duration that could create a relatively homogeneous mixture with $\Phi \approx 0.4$ just before the beginning of a second pulse with $\mathrm{SOI}=334^{\circ} \mathrm{CA}$ ATDC and $6^{\circ} \mathrm{CA}$ duration. The second pulse could finally produce a mixture with $\Phi=0.50$ in the vicinity of the spark plug but also with a high level of turbulence.

- Regardless of injection strategy, the highest flame growth speed was found to be $26-27 \mathrm{~m} / \mathrm{s}$ and occur within $2^{\circ}-4^{\circ}$ $\mathrm{CA}$ after ignition timing (the single injection was fastest to reach this peak). The growth speed decreased gradually after that and this correlated with flame-wall interaction phenomena. This was validated against experimental flame growth data obtained from a similar optical hydrogen engine at the same operating conditions. 
- It was found that the flame speed and flame's propagation direction were related by the velocity field at ignition timing. The impact of fuel stratification was found to be less dominant than the effect imposed by the velocity field. The existence of higher velocity magnitude at ignition timing for the single injection is believed to be the main reason of its faster flame growth than the double-pulse strategy.

- Overall it was found that the injection strategy has a significant effect on the mixture's homogeneity and stratification at ignition timing, but also on the velocity field and turbulence at ignition timing. There is great scope in optimization of the strategy for both mixture and flow-field control that will enable even very lean mixtures to be ignited.

\section{References}

1. White, C.M., Steeper, R.R. and Lutz, A.E., "The hydrogenfueled internal combustion engine: a technical review", International Journal of Hydrogen Energy, Vol. 3, pp. 1292-1305, 2006.

2. Verhelst, S. and Wallner, T., "Hydrogen-fueled internal combustion engines", Progress in Energy and Combustion Science, Vol. 35, pp. 490-527, 2009.

3. Verhelst, S. "Recent progress in the use of hydrogen as a fuel for internal combustion engines", International Journal of Hydrogen Energy, Vol.39, pp. 1071-1085, 2014.

4. Gosselink, J.W. "Pathways to a more sustainable production of energy: sustainable hydrogen-a research objective for Shell", International Journal of Hydrogen Energy, Vol. 27, pp. 1125-1129, 2002.

5. Dincer, I. and Zamfirescu, C., "Sustainable hydrogen production options and the role of IAHE", International Journal of Hydrogen Energy, Vol. 37, pp. 16266-16286, 2012.

6. Chaubey, R., Sahu, S., O. James, O. and Maity, S., "A review on development of industrial processes and emerging techniques for production of hydrogen from renewable and sustainable sources", Renewable and Sustainable Energy Reviews, Vol. 23, pp. 443-462, 2013.

7. Wong, Y.M., Wu, T.Y. and Juan, J.C., "A review of sustainable hydrogen production using seed sludge via dark fermentation", Renewable and Sustainable Energy Reviews, Vol. 34, pp. 471-482, 2014.

8. Verhelst, S., Sierens, R. and Verstraeten, S., "A Critical Review of Experimental Research on Hydrogen Fueled SI Engines", SAE Paper 2006-01-0430, 2006.

9. Bradley, D., Lawes, M., Liu, K., Verhelst S. and Woolley, R., "Laminar burning velocities of lean hydrogen-air mixtures at pressures up to $1.0 \mathrm{MPa}$ ", Combustion and Flame, Vol. 149, pp. 162-172, 2007.

10. Mandilas, C., Ormsby, M.P., Sheppard, C.G.W. and Woolley, R., "Effects of hydrogen addition on laminar and turbulent premixed methane and iso-octane-air flames", Proceedings of the Combustion Institute, Vol. 31, pp. 1443-1450, 2007.

11. Karim, G.A., "Hydrogen as a spark ignition engine fuel", International Journal of Hydrogen Energy, Vol. 28, pp. 569-577, 2003.

12. Rosati, M. and Aleiferis, P., "Hydrogen $\mathrm{SI}$ and $\mathrm{HCCl}$ Combustion in a Direct-Injection Optical Engine," SAE Int. J. Engines, Vol. 2, pp.1710-1736, 2009.
13. Zhenzhong, Y., Lijun, W., Manlou, H. and Yongdi, C., "Research on optimal control to resolve the contradictions between restricting abnormal combustion and improving power output in hydrogen fueled engines", International Journal of Hydrogen Energy, Vol. 37, pp. 774-782, 2012.

14. Zhenzhong, Y., Lijun, W., Zhang, Q., Meng, Y. and Pei, P., "Research on optimum method to eliminate backfire of hydrogen internal combustion engines based on combining postponing ignition timing with water injection of intake manifold", International Journal of Hydrogen Energy, Vol. 37, pp. 12868-12878, 2012.

15. Li, H. and Karim, G.A., "Knock in spark ignition hydrogen engines", International Journal of Hydrogen Energy, Vol. 29, pp. 859-865, 2004.

16. Kawahara, N. and Tomita, E., "Visualization of autoignition and pressure wave during knocking in a hydrogen spark-ignition engine", International Journal of Hydrogen Energy, Vol. 34, pp. 3156-3163, 2009.

17. Berckmüller, M., Rottengruber, H., Eder, A., Brehm, N. et al., "Potentials of a Charged SI-Hydrogen Engine", SAE Technical Paper 2003-01-3210, 2003.

18. Verhelst, S. and Sierens, R., "Combustion Studies for PFI Hydrogen IC Engines", SAE Technical Paper 2007-013610, 2007.

19. Verhelst, S., Maesschalck, P., Rombaut, N. and Sierens, R., "Increasing the power output of hydrogen internal combustion engines by means of supercharging and exhaust gas recirculation", International Journal of Hydrogen Energy, Vol. 34, pp. 4406-4412, 2009.

20. Rakopoulos, C.D., Kosmadakis, G.M. and Pariotis, E.G., "Evaluation of a combustion model for the simulation of hydrogen spark-ignition engines using a CFD code", International Journal of Hydrogen Energy, Vol. 35, pp. 12545-12560, 2010.

21. Rakopoulos, C.D., Kosmadakis, G.M., Demuynck, J., De Paepe, M. et al., "A combined experimental and numerical study of thermal processes, performance and nitric oxide emissions in a hydrogen-fueled spark-ignition engine", International Journal of Hydrogen Energy, Vol. 36, pp. 5163-5180, 2011.

22. Aleiferis, P.G. and Rosati, M.F., "Flame chemiluminescence and $\mathrm{OH}$ LIF imaging in a hydrogenfuelled spark-ignition engine", International Journal of Hydrogen Energy, Vol. 37, pp. 1797-1812, 2012.

23. Wallner, T., Nande, A. and Naber, J., "Evaluation of Injector Location and Nozzle Design in a Direct-Injection Hydrogen Research Engine", SAE Technical Paper 200801-1785, 2008

24. Kaiser, S. and White, C., "PIV and PLIF to Evaluate Mixture Formation in a Direct-Injection Hydrogen-Fuelled Engine", SAE Int. J. Engines, pp. 657-668, 2009.

25. Salazar, V. and Kaiser, S., "An Optical Study of Mixture Preparation in a Hydrogen-fueled Engine with Direct Injection Using Different Nozzle Designs", SAE Int. J. Engines, 119-131, 2010.

26. Scarcelli, R., Wallner, T., Salazar, V., and Kaiser, S., "Modeling and Experiments on Mixture Formation in a Hydrogen Direct-Injection Research Engine", SAE Int. J. Engines, pp. 530-541, 2010.

27. Scarcelli, R., Wallner, T., Matthias, N., Salazar, V. et al., "Mixture Formation in Direct Injection Hydrogen Engines: CFD and Optical Analysis of Single- and Multi-Hole Nozzles", SAE Int. J. Engines, pp. 2361-2375, 2011.

28. Messner, D., Wimmer, A., Gerke, U., and Gerbig, F., "Application and Validation of the 3D CFD Method for a 
Hydrogen Fueled IC Engine with Internal Mixture Formation", SAE Technical Paper 2006-01-0448, 2006.

29. Hamzehloo, A. and Aleiferis, P.G, "Computational Study of Hydrogen Direct Injection for Internal Combustion Engines", SAE Technical Paper 2013-01-2524, 2013.

30. Serras-Pereira, J., Aleiferis, P., Richardson, D., and Wallace, S., "Spray Development, Flow Interactions and Wall Impingement in a Direct-Injection Spark-Ignition Engine", SAE Technical Paper 2007-01-2712, 2007.

31. Rimmer, J., Long, E., Garner, C., Hargrave, G. et al., "The Influence of Single and Multiple Injection Strategies on InCylinder Flow and Combustion within a DISI Engine", SAE Technical Paper 2009-01-0660, 2009

32. Costa, M., Sorge, U. and Allocca, L., "Increasing energy efficiency of a gasoline direct injection engine through optimal synchronization of single or double injection strategies", Energy Conversion and Management, Vol. 60, pp. 77-86, 2012.

33. Alkidas, A.C., "Combustion advancements in gasoline engines", Energy Conversion and Management, Vol. 48, pp. 2751-2761, 2007.

34. Hunicz, J. and Kordos, P., "An experimental study of fuel injection strategies in CAI gasoline engine", Experimental Thermal and Fluid Science, Vol. 35, pp. 243-252, 2011.

35. Aleiferis, P.G. and Rosati, M.F., "Controlled autoignition of hydrogen in a direct-injection optical engine", Combustion and Flame, Vol. 159, pp. 2500-2515, 2012.

36. Kong, S., Marriott, C., Reitz, R. and Christensen, M., "Modeling and Experiments of $\mathrm{HCCl}$ Engine Combustion Using Detailed Chemical Kinetics with Multidimensional CFD", SAE Technical Paper 2001-01-1026, 2001.

37. Kong, S. and Reitz, R.D., "Application of detailed chemistry and CFD for predicting direct injection $\mathrm{HCCl}$ engine combustion and emissions", Proceedings of the Combustion Institute, Vol. 29, pp. 663-669, 2002.

38. Hilbert, R., Tap, F., El-Rabii, H. and Thévenin, D., "Impact of detailed chemistry and transport models on turbulent combustion simulations", Progress in Energy and Combustion Science, Vol. 30, pp. 61-117, 2004.

39. Peters, N., "Laminar Flamelet Concepts in Turbulent Combustion", Twenty-first Symposium (International) on Combustion/The Combustion Institute, pp. 1231-1250, 1986.

40. Duclos, J.M., Veynante, D. and Poinsot, T., "A comparison of flamelet models for premixed turbulent combustion", Combustion and Flame, Vol. 95, pp. 101-117, 1993.

41. Marble, F. E. and Broadwell, J. "The coherent flame model for turbulent chemical reactions", Project SQUID, Rep. TRW-9-PU, 1977.

42. Zhao, X., Matthews, R.D. and Ellzey, J.L, "Numerical Simulations of Combustion in SI Engines: Comparison of the Fractal Model to the Coherent Flame Model", International Symposium COMODIA 94, 1994.

43. Colin, O. and Benkenida, A., "The 3-Zones Extended Coherent Flame Model (ECFM3Z) for Computing Premixed/Diffusion Combustion", Oil \& Gas Science and Technology - Rev. IFP, Vol. 59 pp. 593-609, 2004.

44. Hélie, J. and Trouvé, A., "A modified coherent flame model to describe turbulent flame propagation in mixtures with variable composition", Proceedings of the Combustion Institute, Vol. 28, pp. 193-201, 2000

45. Knop, V., Benkenida, A., Jay, S. and Colin, O., "Modelling of combustion and nitrogen oxide formation in hydrogenfuelled internal combustion engines within a 3D CFD

Page 18 of 21 code", International Journal of Hydrogen Energy, Vol. 33, pp. 5083-5097, 2008.

46. Safari, H., Jazayeri, S.A. and Ebrahimi, R., "Potentials of NOX emission reduction methods in SI hydrogen engines: Simulation study", International Journal of Hydrogen Energy, Vol. 34, pp. 1015-1025, 2009.

47. Verhelst, S., T'Joen, C., Vancoillie, J. and Demuynck, J., "A correlation for the laminar burning velocity for use in hydrogen spark ignition engine simulation", International Journal of Hydrogen Energy, Vol. 36, pp. 957-974, 2011.

48. Kosmadakis, G.M., Rakopoulos, C.D., Demuynck, J., M. De Paepe et al, "CFD modeling and experimental study of combustion and nitric oxide emissions in hydrogen-fueled spark-ignition engine operating in a very wide range of EGR rates", International Journal of Hydrogen Energy, Vol. 37, pp. 10917-10934, 2012.

49. Liu, X., Ji, C., Gao, B., Wang, S. et al, "A laminar flame speed correlation of hydrogen-methanol blends valid at engine-like conditions", International Journal of Hydrogen Energy, Vol. 38, pp. 15500--15509, 2013.

50. Duan, J., Liu, F. and Sun, B., "Backfire control and power enhancement of a hydrogen internal combustion engine", International Journal of Hydrogen Energy, Vol. 39, pp. 4581-4589, 2014.

51. Noda, T. and Foster, D., "A Numerical Study to Control Combustion Duration of Hydrogen-Fueled HCCl by Using Multi-Zone Chemical Kinetics Simulation", SAE Technical Paper 2001-01-0250, 2001.

52. Liu, C. and Karim, G.A., "A simulation of the combustion of hydrogen in $\mathrm{HCCl}$ engines using a 3D model with detailed chemical kinetics", International Journal of Hydrogen Energy, Vol. 33, pp. 3863-3875, 2008.

53. Boretti, A.A., "Modelling auto ignition of hydrogen in a jet ignition pre-chamber", International Journal of Hydrogen Energy, Vol. 35, pp. 3881-3890, 2010.

54. Boretti, A.A., "Vehicle driving cycle performance of the spark-less di-ji hydrogen engine", International Journal of Hydrogen Energy, Vol. 35, pp. 4702-4714, 2010.

55. Boretti, A.A., "Stochastic reactor modelling of multi modes combustion with diesel direct injection or hydrogen jet ignition start of combustion", International Journal of Hydrogen Energy, Vol. 37, pp. 13555-13563, 2012.

56. http://www.cd-adapco.com/products/star-ccm ${ }^{\circledR}$ [retrieved 01/04/2014].

57. Hamzehloo, A., and Aleiferis, P.G., "Large Eddy Simulation of Near-Nozzle Shock Structure and Mixing Characteristics of Hydrogen Jets for Direct-Injection Spark-Ignition Engines", 10th International Conference on Heat Transfer, Fluid Mechanics and Thermodynamics (HEFAT2014), Orlando, Florida, USA, 2014.

58. Hamzehloo, A., and Aleiferis, P.G., "Large Eddy Simulation of Highly Turbulent Under-Expanded Hydrogen and Methane Jets for Gaseous-Fuelled Internal Combustion Engines", International Journal of Hydrogen Energy., 2014, submitted.

59. Menter, F.R., "Two-equation eddy-viscosity turbulence modeling for engineering applications", AIAA Journal, Vo. 32, pp. 1598-1605, 1994

60. Chin C., Li M., Harkin C., Rochwerger T. et al, "Investigation of the Flow Structures in Supersonic Free and Impinging Jet Flows", Journal of Fluids Engineering, Vol. 135, 2013.

61. Gorlé C. and laccarino G., "Large eddy and ReynoldsAveraged Navier-Stokes simulations of an underexpanded sonic jet", 7th European Symposium on 
Aerothermodynamics, European Space Agency, Netherlands, 2011.

62. http://www.cd-adapco.com/products/star-®/dars [retrieved 01/04/2014].

63. Balakrishnan, G., Smooke, M.D. and Williams, F.A., "A numerical investigation of extinction and ignition limits in laminar nonpremixed counterflowing hydrogen-air streams for both elementary and reduced chemistry", Combustion and Flame, Vol. 102, pp. 329-340, 1995.

64. Mueller, M.A., Yetter, R.A. and Dryer, F.L., "Kinetic modeling of the $\mathrm{CO} / \mathrm{H} 2 \mathrm{O} / \mathrm{O} 2 / \mathrm{NO} / \mathrm{SO} 2$ system: Implications for high-pressure fall-off in the $\mathrm{SO} 2+\mathrm{O}(+\mathrm{M})=\mathrm{SO} 3(+\mathrm{M})$ reaction", International Journal of Chemical Kinetics, Vol. 32, pp. 317-339, 2000.

65. Li, J., Zhao, A. and, Kazakov, A., "An updated comprehensive kinetic model of hydrogen combustion", International Journal of Chemical Kinetics, Vol. 36, pp. 566-575, 2004.

66. Konnov, A.A., "Remaining uncertainties in the kinetic mechanism of hydrogen combustion", Combustion and Flame, Vol. 152, pp. 507-528, 2008.

67. Shatalov, O.P, Ibraguimova, L.B, Pavlov, V.A., Smekhov, G.D. et al, "Analysis of the Kinetic Data Described Oxygen-Hydrogen Mixtures Combustion", Proceedings of the European Combustion Meeting, 2009.

68. Knio, O.M., Najm, H.N. and Wyckoff, P.S., "A Semi-implicit Numerical Scheme for Reacting Flow: II. Stiff, OperatorSplit Formulation", Journal of Computational Physics, Vol. 154, pp. 428-467, 1999.

69. İlbas, M., Yılmaz, İ. and Kaplan, Y., "Investigations of hydrogen and hydrogen-hydrocarbon composite fuel combustion and emission characteristics in a model combustor", International Journal of Hydrogen Energy, Vol. 30, pp. 1139-1147, 2005.

70. Malcolm, J., Behringer, M., Aleiferis, P.G., Mitcalf, J. et al., "Characterisation of Flow Structures in a Direct-Injection Spark-Ignition Engine Using PIV, LDV and CFD," SAE Technical Paper 2011-01-1290, 2011

71. Aleiferis, P.G., Serras-Pereira, J., van Romunde, Z., Caine, J. et al. , "Mechanisms of spray formation and combustion from a multi-hole injector with E85 and gosiline", Combustion and Flame, Vol. 157, pp. 735-756., 2010.

72. Anderson J. D., "Modern compressible flow: with historical prespective, 3rd Edition", McGraw-Hill, 2003.

73. Yu, J., Vuorinen, V., Hillamo, H., Sarjovaara, T. et al., "An Experimental Study on High Pressure Pulsed Jets for DI Gas Engine Using Planar Laser-Induced Fluorescence", SAE Technical Paper 2012-01-1655, 2012.
74. Hamzehloo, A., "Computational Study of Mixture Formation and Combustion in Hydrogen-Fuelled Direct Injection Spark Ignition Engines", Ph.D. Thesis, University College London (UCL), UK (in Preparation).

75. Verhelst, S., Woolley, R., Lawes, M. and Sierens, R., "Laminar and unstable burning velocities and Markstein lengths of hydrogen-air mixtures at engine-like conditions", Proceedings of the Combustion Institute, Vol. 30, pp. 209-216, 2005.

76. Owston, R., Magi, V. and Abraham, J., "Fuel-Air Mixing Characteristics of DI Hydrogen Jets", SAE Int. J. Engines, pp. 693-712, 2009.

77. Gregory-Smith, D.G and Gilchrist, A.R., "The compressible Coanda wall jet-an experimental study of jet structure and breakaway", International Journal of Heat and Fluid Flow, Vol. 8. pp. 156-164, 1987.

78. Hu, E., Huang, Z., He, J., Miao, H. "Experimental and numerical study on laminar burning velocities and flame instabilities of hydrogen-air mixtures at elevated pressures and temperatures", International Journal of Hydrogen Energy, Vol. 34, pp. 8741-8755, 2009.

\section{Contact Information}

Author for correspondence:

Dr. Pavlos Aleiferis

Department of Mechanical Engineering

University College London (UCL)

Torrington Place

London WC1E 7JE

United Kingdom

p.aleiferis@ucl.ac.uk

\section{Acknowledgments}

The authors acknowledge the use of University College London's Legion High Performance Computing Facility (Legion@UCL), and associated support services, in the completion of this work. The CAD engine geometry is based on MAHLE Powertrain's single-cylinder optical research engine; use of this geometry for the scope of the current work is gratefully acknowledged. The authors would also like to thank all members of the UCL Internal Combustion Engines Group for their assistance and many useful discussions. 


\section{Definitions/Abbreviations}

A

Arrhenius pre-exponential factor

AIT

ATDC

ASOI

BTDC

CA

CFD

CFM

co

$\mathrm{CO}_{2}$

DARS

DI

DISI

$E_{\mathrm{a}}$

ECFM

EOI

FFM

$\mathrm{HCCl}$

IC

IT

k

K

Le

LES

m
After ignition timing

After top dead center

After start of injection

Before top dead center

Crank angle

Computational fluid dynamics

Coherent flame model

Carbon monoxide

Carbon dioxide

Digital analysis of reaction systems

Direct injection

Direct injection spark ignition

Arrhenius activation energy

Extended coherent flame model

End of injection

Fractal flame model

Homogeneous charge compression ignition

Internal combustion

Ignition timing

Turbulent kinetic energy

Arrhenius reaction rate

Lewis number

Large eddy simulation

Mass of species
$\mathrm{NO}_{\mathrm{x}}$

ODE

$P_{0}$

$P_{M}$

PFI

PM

$\boldsymbol{R}$

RANS

ROI

$S$

SI

Sol

$T$

$T_{M}$

TDC

TKE

UHC

$V_{M}$

$Y_{N}$

$\rho$

$\Phi$

$x$

$\omega$

$\omega_{N}$

$\circ$
Mach number

Arrhenius temperature exponent

Nitrogen oxide emissions

Ordinary differential equation

Total injection pressure

Mixture pressure

Port fuel injection

Particulate matter

Specific gas constant

Reynolds-averaged

Navier-Stokes

Rate of injection

Equivalent flame speed

Spark ignition

Start of injection

Temperature

Mixture temperature

Top dead center

Turbulent kinetic energy

Unburned hydrogen carbon

Mixture volume

Mass fraction of the $\mathrm{N}^{\text {th }}$ specie

Density

Equivalence ratio

Mole fraction

turbulent dissipation

Rate of production of species $\mathrm{N}$

Degree sign 


\section{Appendix}

Table 1. Detailed $\mathrm{H}_{2}-\mathrm{O}_{2}$ reaction mechanism in $\mathrm{N}_{2}$ as the main bath gas.

\begin{tabular}{|c|c|c|c|c|c|c|c|}
\hline \multirow[b]{2}{*}{$\mathrm{R}$} & \multirow{2}{*}{ Formulation } & \multicolumn{3}{|c|}{ Arrhenius coefficients for the forward reaction } & \multicolumn{3}{|c|}{ Arrhenius coefficients for the backward reaction } \\
\hline & & $A$ & $n$ & $E_{a}$ & $A$ & & $E_{a}$ \\
\hline 1 & $\mathrm{H}_{2}+\mathrm{O}_{2}=\mathrm{OH}+\mathrm{OH}$ & $1.700 \times 10^{13}$ & $+0.000 \times 10^{00}$ & $+1.999 \times 10^{02}$ & $2.223 \times 10^{10}$ & $+3.877 \times 10^{-01}$ & $+1.202 \times 10^{0}$ \\
\hline 2 & $\mathrm{H}_{2}+\mathrm{OH}=\mathrm{H}_{2} \mathrm{O}+\mathrm{H}$ & $1.170 \times 100^{9}$ & $+1.300 \times 10^{00}$ & $+1.517 \times 10^{01}$ & $7.980 \times 10^{10}$ & $+9.726 \times 10^{-01}$ & $+8.200 \times 10^{0}$ \\
\hline 3 & $\mathrm{H}+\mathrm{O}_{2}=\mathrm{OH}+\mathrm{O}$ & $2.000 \times 10^{14}$ & $+0.000 \times 10^{00}$ & $+7.029 \times 10^{01}$ & $6.712 \times 10^{11}$ & $+3.742 \times 10^{-01}$ & $-1.190 \times 10^{00}$ \\
\hline 4 & $\mathrm{O}+\mathrm{H}_{2}=\mathrm{OH}+\mathrm{H}$ & $1.800 \times 10^{10}$ & $+1.000 \times 10^{00}$ & $+3.693 \times 10^{01}$ & $7.014 \times 10^{09}$ & $+1.014 \times 10^{00}$ & $+2.866 \times 10^{0}$ \\
\hline 5 & $\mathrm{H}+\mathrm{O}_{2}+\mathrm{M}_{\mathrm{a}}=\mathrm{HO}_{2}+\mathrm{M}^{\mathrm{a}}$ & $2.100 \times 10^{18}$ & $-1.000 \times 10^{00}$ & $+0.000 \times 10^{00}$ & $6.276 \times 10^{20}$ & $-1.660 \times 10^{00}$ & $+2.142 \times 10^{0 .}$ \\
\hline 6 & $\mathrm{H}+\mathrm{O}_{2}+\mathrm{O}_{2}=\mathrm{HO}_{2}+\mathrm{O}_{2}$ & $6.700 \times 10^{19}$ & $-1.420 \times 10^{00}$ & $+0.000 \times 10^{00}$ & $2.002 \times 10^{22}$ & $-2.080 \times 10^{00}$ & $+2.142 \times 10^{0}$ \\
\hline 7 & $\mathrm{H}+\mathrm{O}_{2}+\mathrm{N}_{2}=\mathrm{HO}_{2}+\mathrm{N}_{2}$ & $6.700 \times 10^{19}$ & $-1.420 \times 10^{00}$ & $+0.000 \times 10^{00}$ & $2.002 \times 10^{22}$ & $-2.080 \times 10^{00}$ & $+2.142 \times 10^{0 .}$ \\
\hline 8 & $\mathrm{OH}+\mathrm{HO}_{2}=\mathrm{H}_{2} \mathrm{O}+\mathrm{O}_{2}$ & $5.000 \times 10^{13}$ & $+0.000 \times 10^{00}$ & $+4.184 \times 10^{00}$ & $4.033 \times 10^{14}$ & $+7.798 \times 10^{00}$ & $+2.972 \times 10^{0}$ \\
\hline 9 & $\mathrm{H}+\mathrm{HO}_{2}=\mathrm{OH}+\mathrm{OH}$ & $2.500 \times 10^{14}$ & $+0.000 \times 10^{00}$ & $+7.950 \times 10^{00}$ & $3.867 \times 10^{10}$ & $+7.930 \times 10^{-01}$ & $+1.544 \times 10^{0}$ \\
\hline 10 & $\mathrm{O}+\mathrm{HO}_{2}=\mathrm{O}_{2}+\mathrm{OH}$ & $4.800 \times 10^{13}$ & $+0.000 \times 10^{00}$ & $+4.184 \times 10^{00}$ & $2.212 \times 10^{12}$ & $+4.189 \times 10^{-01}$ & $+2.221 \times 10^{0}$ \\
\hline 11 & $\mathrm{OH}+\mathrm{OH}=\mathrm{O}+\mathrm{H}_{2} \mathrm{O}$ & $6.000 \times 10^{08}$ & $+1.300 \times 10^{0}$ & $+0.000 \times 10^{00}$ & $1.050 \times 10^{11}$ & $+9.591 \times 10^{-01}$ & $+7.510 \times 10^{0}$ \\
\hline 12 & $\mathrm{H}_{2}+\mathrm{M}_{\mathrm{b}}=\mathrm{H}+\mathrm{H}+\mathrm{M}^{\mathrm{b}}$ & $2.230 \times 10^{12}$ & $+5.000 \times 10^{-01}$ & $+3.874 \times 10^{02}$ & $6.310 \times 10^{10}$ & $+7.542 \times 10^{-01}$ & $-5.301 \times 10^{01}$ \\
\hline 13 & $\mathrm{O} 2+\mathrm{M}=\mathrm{O}+\mathrm{O}+\mathrm{M}$ & $1.850 \times 10^{11}$ & $+5.000 \times 10^{-01}$ & $+3.998 \times 10^{02}$ & $4.508 \times 10^{0 /}$ & $+1.115 \times 10^{00}$ & $-1.038 \times 10^{02}$ \\
\hline 14 & $\mathrm{H}+\mathrm{OH}+\mathrm{M}_{\mathrm{c}}=\mathrm{H}_{2} \mathrm{O}+\mathrm{M}^{\mathrm{c}}$ & $7.500 \times 10^{23}$ & $-2.600 \times 10^{00}$ & $+0.000 \times 10^{00}$ & $1.808 \times 10^{21}$ & $-3.182 \times 10^{00}$ & $+5.073 \times 10^{0}$ \\
\hline 15 & $\mathrm{H}+\mathrm{HO}_{2}=\mathrm{H}_{2}+\mathrm{O}_{2}$ & $2.500 \times 10^{13}$ & $0.000 \times 10^{00}$ & $+2.929 \times 10^{00}$ & $2.956 \times 10^{12}$ & $+4.053 \times 10^{00}$ & $+2.292 \times 10^{00}$ \\
\hline 16 & $\mathrm{HO}_{2}+\mathrm{HO}_{2}=\mathrm{H}_{2} \mathrm{O}_{2}+\mathrm{O}_{2}$ & $2.000 \times 10^{12}$ & $0.000 \times 10^{00}$ & $+0.000 \times 10^{00}$ & $5.131 \times 10^{13}$ & $-1.776 \times 10^{-01}$ & $+1.553 \times 10^{0}$ \\
\hline 17 & $\mathrm{H}_{2} \mathrm{O}_{2}+\mathrm{M}=\mathrm{OH}+\mathrm{OH}+\mathrm{M}$ & $1.300 \times 10^{17}$ & $0.000 \times 10^{00}$ & $+1.904 \times 10^{02}$ & $2.622 \times 10^{09}$ & $+1.630 \times 10^{00}$ & $-3.268 \times 10^{01}$ \\
\hline 18 & $\mathrm{H}_{2} \mathrm{O}_{2}+\mathrm{H}=\mathrm{HO}_{2}+\mathrm{H}_{2}$ & $1.600 \times 10^{12}$ & $0.000 \times 10^{00}$ & $+1.590 \times 10^{01}$ & $7.375 \times 10^{09}$ & $+5.829 \times 10^{-01}$ & $+8.682 \times 10^{0}$ \\
\hline 19 & $\mathrm{H}_{2} \mathrm{O}_{2}+\mathrm{OH}=\mathrm{H}_{2} \mathrm{O}+\mathrm{HO}_{2}$ & $1.000 \times 10^{13}$ & $0.000 \times 10^{00}$ & $+7.531 \times 10^{00}$ & $3.144 \times 10^{12}$ & $+2.556 \times 10^{-01}$ & $+1.453 \times 10^{0}$ \\
\hline \multicolumn{8}{|c|}{ 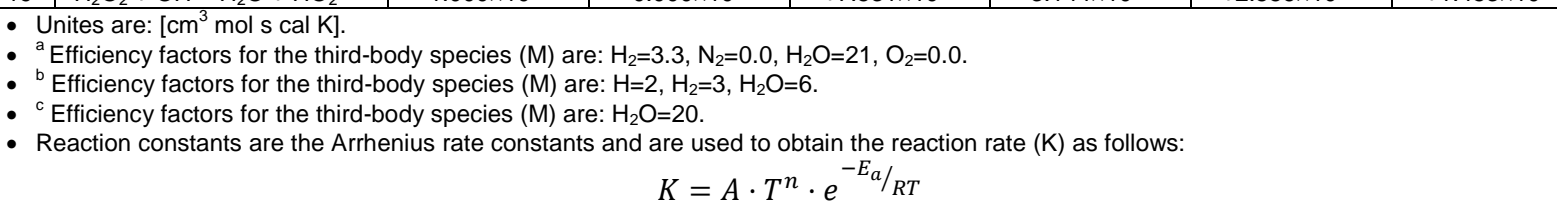 } \\
\hline
\end{tabular}

Page 21 of 21 